OPEN ACCESS

Edited by:

Rex Brennan,

The James Hutton Institute, UK

Reviewed by:

Andrew Nick Birch,

The James Hutton Institute, UK

Julie Graham,

The James Hutton Institute, UK

Michelle Fountain,

NIAB East Malling Research, UK

*Correspondence:

Julie A. Peterson

julie.peterson@unl.edu

Specialty section:

This article was submitted to Crop Science and Horticulture,

a section of the journal

Frontiers in Plant Science

Received: 18 March 2016 Accepted: 15 November 2016

Published: 30 November 2016

Citation:

Peterson JA, Ode PJ,

Oliveira-Hofman $C$ and Harwood JD (2016) Integration of Plant Defense

Traits with Biological Control of Arthropod Pests: Challenges and Opportunities.

Front. Plant Sci. 7:1794. doi: 10.3389/fpls.2016.01794

\section{Integration of Plant Defense Traits with Biological Control of Arthropod Pests: Challenges and Opportunities}

\author{
Julie A. Peterson ${ }^{*}$, Paul J. Ode ${ }^{2}$, Camila Oliveira-Hofman ${ }^{3}$ and James D. Harwood ${ }^{4}$ \\ 1 Department of Entomology, West Central Research and Extension Center, University of Nebraska-Lincoln, North Platte, \\ NE, USA, ${ }^{2}$ Department of Bioagricultural Sciences and Pest Management, Colorado State University, Fort Collins, CO, USA, \\ ${ }^{3}$ Department of Entomology, University of Nebraska-Lincoln, Lincoln, NE, USA, ${ }^{4}$ Department of Entomology, University of \\ Kentucky, Lexington, KY, USA
}

Crop plants exhibit a wide diversity of defensive traits and strategies to protect themselves from damage by herbivorous pests and disease. These defensive traits may be naturally occurring or artificially selected through crop breeding, including introduction via genetic engineering. While these traits can have obvious and direct impacts on herbivorous pests, many have profound effects on higher trophic levels, including the natural enemies of herbivores. Multi-trophic effects of host plant resistance have the potential to influence, both positively and negatively, biological control. Plant defense traits can influence both the numerical and functional responses of natural enemies; these interactions can be semiochemically, plant toxin-, plant nutrient-, and/or physically mediated. Case studies involving predators, parasitoids, and pathogens of crop pests will be presented and discussed. These diverse groups of natural enemies may respond differently to crop plant traits based on their own unique biology and the ecological niches they fill. Genetically modified crop plants that have been engineered to express transgenic products affecting herbivorous pests are an additional consideration. For the most part, transgenic plant incorporated protectant (PIP) traits are compatible with biological control due to their selective toxicity to targeted pests and relatively low nontarget impacts, although transgenic crops may have indirect effects on higher trophic levels and arthropod communities mediated by lower host or prey number and/or quality. Host plant resistance and biological control are two of the key pillars of integrated pest management; their potential interactions, whether they are synergistic, complementary, or disruptive, are key in understanding and achieving sustainable and effective pest management.

Keywords: host plant resistance, tritrophic interactions, transgenic crops, biological control, herbivore-induced plant volatiles (HIPVs)

\section{INTRODUCTION TO KEY CONCEPTS}

The worldwide population is growing, with projections of 9-10 billion people living on Earth by 2050 (United Nations, 2004; Lutz and Samir, 2010). Global food demands are increasing concomitantly, with a need for heightened food security, increased agricultural productivity and improved water use efficiency of crops. In a global review of factors contributing to losses for eight 
major food and cash crops, animal pests came in second only to weeds, causing potential yield losses of $17.6 \%$ (Oerke and Dehne, 2004). Clearly, crop pests are responsible for significant losses to agricultural commodities worldwide despite profound efforts at management. Identification and promotion of sustainable solutions to these agricultural threats are essential for meeting future needs. The concepts of Integrated Pest Management (IPM), first championed by Stern et al. (1959), support practical efforts to achieve sustainable pest management. IPM has been described as "the harmonious use of multiple methods to control" pests, using "a set of decision rules based on ecological principles and economic and social considerations" (Kogan, 1998). Ideally, IPM incorporates the use of economic thresholds (Higley and Peterson, 2009) and a variety of control tactics (mechanical, physical, cultural, chemical, biological, and host plant resistance) making it essential to understand the interactions between different control tactics. Two key approaches for sustainable pest management have been (1) host plant resistance, the selection or development (via traditional breeding or genetic modification) and use of crop plants that possess defensive traits against herbivores and disease, and (2) biological control, the use of living organisms that are natural enemies of crop pests.

The concept of breeding plants to select for heritable traits that reduce pest impacts has been a part of agricultural production for over 100 years (Painter, 1951; Smith, 2005) and can be separated into tolerance and resistance mechanisms (Stout, 2013). Tolerance allows plants to withstand pest injury while resistance is conferred by plant traits that reduce the extent of pest injury and can be divided into constitutive or inducible and direct or indirect plant defenses (Stout, 2013). A constitutive defense is expressed in a plant regardless of whether it has been attacked by an herbivore, whereas an inducible defense is only expressed (or expressed to a greater degree) after attack. Direct defenses affect the herbivore without a mediating factor, whereas indirect defenses act via the actions of natural enemies. While indirect resistance may have the most obvious implications for biological control, other forms of resistance and tolerance also impact pest control by natural enemies. Holistic consideration of all these mechanisms is critical for their successful integration into pest control schemes.

Biological control programs use natural enemies (predators, parasitoids, and pathogens) of targeted pests to keep populations below the economic threshold. Classical biological control is the importation and establishment of natural enemies to control exotic pests while augmentation biological control incorporates the supplemental release of natural enemies. Conservation biological control involves modification of the environment or existing agronomic practices to protect and enhance specific natural enemies already present in the ecosystem (e.g., Landis et al., 2000; Eilenberg et al., 2001). The maintenance of natural enemy populations via conservation biological control can be a practical and sustainable option for low-value and highacreage commodities, such as maize and other annual field crops (Thorbek et al., 2004; Naranjo et al., 2015). The responses of natural enemies to pest population changes are critically important and these can be classified as numerical (changes in natural enemy abundance due to reproduction or aggregation) or functional (changes in natural enemy behavior) (Hajek, 2004). Seminal work on functional responses of predators to their prey items by Holling (1966) demonstrated that rate of prey discovery, search time, handling time, and predator hunger were important factors in determining functional response. In the years since Holling's research, studies in pest management have frequently examined how predators respond to prey, documenting the existence of functional responses in the context of biological control (e.g., De Clercq et al., 2000; Lee and Kang, 2004; Rutledge and O’Neil, 2005). Interestingly, some studies also describe variable responses of predators on different plants using plantbased defenses such as glandular trichomes and allelochemical production (De Clercq et al., 2000). These variable responses therefore highlight the need for careful consideration of the effects of different plant traits on pest suppression.

The interactions between plants, herbivores, and their natural enemies are referred to as tritrophic interactions and this multi-trophic exchange is key to understanding the interactions between host plant resistance and biological control. Natural enemies can be considered an extension of plant defense if plant traits, such as release of herbivore-induced plant volatiles (HIPVs), draw in these natural enemies. The literature is replete with examples of natural enemies acting in a top-down fashion, reducing herbivore populations, thereby providing plant defense.

The intention of this section is to provide a general introduction to the key concepts that provide context for the remainder of this review article. For more in-depth discussion of these topics, please refer to the many texts that review these topics (i.e., Painter, 1951; Panda and Khush, 1995; Kogan, 1998; Bellows et al., 1999; Agrawal, 2000a; Landis et al., 2000; Hajek, 2004; Smith, 2005; Heil, 2008; Radcliffe et al., 2009; van Lenteren, 2012; Stout, 2013; Pedigo and Rice, 2014). This review will focus on the interactions between biological control and host plant resistance, addressing the mechanisms and potential outcomes of interactions, with special attention to genetically modified insectresistant crops and case studies for application of host plant resistance and biological control in cropping systems.

\section{IMPACT OF PLANT TRAITS ON BIOLOGICAL CONTROL}

The mechanisms by which plant defensive traits can affect biological control can be divided into four major categories: semiochemically, plant toxin-, plant nutrient-, and physically mediated interactions. These have been widely recognized as the major mechanisms by which the three trophic levels interact (Price, 1986; Thomas and Waage, 1996; Agrawal, 2000a) and will be reviewed in detail here. Their integration (see Discussion) into biological control programs is critical as we develop sustainable solutions for pest management.

\section{Semiochemically Mediated Interactions}

Plants produce a wide range of volatile compounds that are the predominant signals used by arthropod herbivores to 
locate suitable host plants (Schoonhoven et al., 2005). These volatile profiles can change both quantitatively and qualitatively following herbivory (Dicke, 1999; Páre and Tumlinson, 1999; Heil and Ton, 2008), dramatically altering their attractiveness (or repellency) to herbivores and their natural enemies (Heil, 2014). Feeding, especially by chewing herbivores, results in mechanical damage to plant tissues eliciting a wound response thereby creating electrical, hydraulic, and chemical signals (e.g., systemin; Kessler and Baldwin, 2002). This action results in local and systemic release of linolenic acid from plant cell membranes and is converted by the enzyme lipoxygenase (LOX) to 13-hydroperoxide, which enters one of two pathways (Walling, 2000; Kessler and Baldwin, 2002). In one pathway, 13-hydroperoxide may be hydrolyzed by hydroperoxide lyase to yield 'green leaf volatiles' (GLVs; e.g., $\mathrm{C}_{6}$ alcohols and aldehydes) and these, and other volatiles such as terpenoids, are often considered indirect defenses because they attract natural enemies. Alternatively, 13-hydroperoxide can enter the octadecanoid pathway, resulting in the production of jasmonic acid (JA), ultimately producing an array of antiherbivore defenses including proteinase inhibitors (anti-digestive proteins), polyphenol oxidases (anti-nutritive enzymes), and a bewildering diversity of plant-specific toxins (Walling, 2000; Kessler, 2015; see Plant Toxin-Mediated Interactions). These inducible defensive chemicals are generally termed direct defenses in that they directly deter or inhibit feeding by herbivores.

Yet, plant responses to herbivory are more complex than simple wound responses to mechanical damage, which cannot explain the specificity of some plant responses to herbivores. In addition to physical damage, herbivores secrete substances that may modify plant responses. Collectively, these substances are referred to as herbivore-associated molecular patterns (HAMPs; Felton and Tumlinson, 2008; Mithöfer and Boland, 2008) and include substances such as regurgitants and salivary secretions (Alborn et al., 1997; Musser et al., 2002; Schäfer et al., 2011; Tian et al., 2012; Louis et al., 2013), and even frass production (Ray et al., 2015). Behavioral interactions, too, modify plant volatile production with walking on leaf surfaces (Tooker et al., 2010) and oviposition (Hilker and Meiners, 2006; Kim et al., 2012; Hilfiker et al., 2014) having profound effects. It is therefore unsurprising that plants respond to herbivory in specific ways that provide informative semiochemical-based information for both herbivores and their natural enemies. Plants emit different suites of volatiles, attracting different parasitoid complexes, depending on the species of herbivore attacking the plant. Clearly, there is abundant evidence that HAMPs and behavioral interactions of herbivores with host plants alter plant defensive responses beyond that of simple mechanical damage (e.g., Dicke, 1999; Reymond et al., 2000; Kessler and Baldwin, 2002). This highlights a cautionary note when interpreting findings of the large number of ecological studies using artificial leaf clippings and hole punches as a proxy for herbivore damage.

As discussed above, plant volatiles that attract natural enemies are considered indirect defenses (Vet and Dicke, 1992; Kessler and Baldwin, 2002; Turlings and Wäckers, 2004;
Wäschke et al., 2013). These GLVs, and others produced via different pathways such as volatile terpenoids (Kessler and Baldwin, 2002; Dudareva et al., 2013; Kessler, 2015), play a crucial role in signaling specific information for parasitoids regarding the status of herbivores and their natural enemies. The information conveyed in HIPVs can provide information on the species of herbivore present, the level of herbivory damage sustained, the developmental stage of the host, and even whether the herbivore has been previously parasitized. For instance, tomato plants attacked by tobacco budworm Heliothis virescens (F.) (Lepidoptera: Noctuidae), but not the closely related tomato fruitworm Helicoverpa zea (Boddie) (Lepidoptera: Noctuidae), emit a volatile profile that is highly attractive to the specialist parasitoid of the tobacco budworm, Cardiochiles nigriceps Viereck (Hymenoptera: Braconidae) (De Moraes et al., 1998). Such information conveyed to natural enemies has profound consequences for the biological control services afforded by them and maximizes the top-down effect of such species on herbivorous pests. The quantity of HIPVs released may reflect the level of herbivory and determine the level of attractiveness to parasitoids. In studies of Cotesia glomerata (L.) (Hymenoptera: Braconidae) attacking Pieris rapae (L.) (Lepidoptera: Pieridae), plants attacked by more herbivores or induced with higher concentrations of JA (simulating higher levels of herbivory) were more attractive to C. glomerata (Geervliet et al., 1998; Bruinsma et al., 2009). Yet, HIPV production may also influence the plant's attractiveness to herbivores. In an interesting study of two chrysomelid beetles (Gynandrobrotica guerreroensis (Jacoby) and Cerotoma ruficornis Olivier) attacking wild lima beans [Phaseolus lunatus L. (Fabales: Fabaceae)], female beetles were repelled by HIPVs produced by induced plants regardless of level of induction (possibly reflecting competition and a lack of enemy-free space) whereas males were attracted by weakly induced plants (possibly indicating the presence of a mate) but repelled by strongly induced plants (Ballhorn et al., 2013). The effect of such changes in herbivore densities on parasitoid foraging decisions is unexplored. Furthermore, parasitoid species identity may also influence plant volatile production. Cabbage [Brassica oleracea L. (Brassicales: Brassicaceae)] produced similar HIPV profiles when attacked by imported cabbageworm Pieris rapae (L.) or large cabbage white P. brassicae (L.) (Lepidoptera: Pieridae) (Poelman et al., 2011). Yet, intriguingly, herbivore regurgitant characteristics were strongly influenced by the species of parasitoid developing within the herbivore, which differentially expressed genes within the plant's JA-signaling pathway. Even hyperparasitoids use HIPVs to locate their parasitoid hosts; the hyperparasitoid Lysibia nana Gravenhorst (Hymenoptera: Ichneumonidae) was more attracted to P. rapae hosts attacked by C. glomerata than those attacked by C. rubecula or unparasitized hosts. Field surveys showed hosts parasitized by C. glomerata are more likely to be hyperparasitized than C. rubecula-parasitized hosts and this preference was due to differences in HIPV profiles elicited by the oral secretions of $P$. rapae (Poelman et al., 2012). The sheer complexity of such semiochemically mediated interactions demonstrates the need for consideration of the multitude of 
factors influencing pest control, rather than single elements acting along.

\section{Case study: Maize Volatiles, Western Corn Rootworm, and Entomopathogenic Nematodes}

Domestication can inadvertently alter the volatile profiles of many crop plants, affecting rates of parasitism. One example is the production of the sesquiterpene (E)- $\beta$-caryophyllene (E $\beta C$ ) in maize. $\mathrm{E} \beta \mathrm{C}$ is emitted in response to above- (Turlings et al., 1998) and below-ground injury (Rasmann et al., 2005). It serves as an attractant for natural enemies of maize pests (Rasmann et al., 2005; Köllner et al., 2008) and provides protection from herbivores with different modes and sites of attack (Köllner et al., 2008). Unfortunately, E $\beta C$ production has been unintentionally bred out of commercially available North American maize hybrids, but it is still present in European maize lines and teosinte (Zea mays ssp. parviglumis) (Degen et al., 2004; Rasmann et al., 2005). E $\beta C$ production can be reintroduced by insertion of a gene from oregano, Origanum vulgare L. (Lamiales: Lamiaceae) (Degenhardt et al., 2009), demonstrating the ability to genetically enhance crops to increase natural enemy control of insect pests.

The most challenging belowground pest of maize production in North America and Europe is the western corn rootworm (WCR) Diabrotica virgifera virgifera LeConte (Coleoptera: Chrysomelidae). Upon injury to the roots, European maize hybrids induce a strong production of $\mathrm{E} \beta \mathrm{C}$ locally and a weak systemic response throughout root tissues (Hiltpold et al., 2011). $\mathrm{E} \beta \mathrm{C}$ released into the rhizosphere recruits the entomopathogenic nematode (EPN) Heterorhabditis megidis Poinar, Jackson and Klein (Rhabditida: Heterorhabditidae). In field studies, maize hybrids producing $\mathrm{E} \beta \mathrm{C}$ had significantly higher rates of H. megidis infection in WCR larvae and reduced rootworm adult emergence than non-E $\beta C$-emitting hybrids; non-E $\beta C$-emitting maize varieties do not recruit $H$. megidis when attacked by the WCR (Rasmann et al., 2005).

Numerous studies have shown the potential of EPNs to suppress WCR populations (Wright et al., 1993; Jackson, 1996; Toepfer et al., 2005, 2008; Kurtz et al., 2009; Hiltpold et al., 2012) but not all EPN species and strains that attack WCR larvae are attracted to E $\beta C$ (Hiltpold et al., 2010c; Anbesse and Ehlers, 2013; Laznik and Trdan, 2013). Heterorhabditis bacteriophora Poinar (Rhabditida: Heterorhabditidae), for instance, is highly effective against WCR larvae (Jackson, 1996; Toepfer et al., 2008; Pilz et al., 2009) but is not attracted to E $\beta C$ (Hiltpold et al., 2010a,c). Selective breeding of $H$. bacteriophora, however, can increase the attraction of infective juveniles to $\mathrm{E} \beta \mathrm{C}$-emitting maize roots, thereby increasing WCR mortality (Hiltpold et al., 2010a,b).

Maximizing the expression of HIPVs via bioengineering, while increasing EPN responsiveness to volatiles, can help enhance the effectiveness of biological control in crops. However, more studies are needed to assess the costs, viability and potential risks of introducing $\mathrm{E} \beta \mathrm{C}$-emitting maize varieties with EPN releases. The WCR has a high propensity for invasion and adaptation (Gray et al., 2009) and has already developed resistance to multiple chemical (Meinke et al., 1998; Ciosi et al., 2009; Pereira et al., 2015), genetic (Gassmann et al., 2011; Wangila et al., 2015), and cultural (Levine et al., 2002) management tools. Alternative control strategies, such as recruitment of entomopathogens using plant volatiles, must be explored in order to sustainably manage this critical pest.

\section{Plant Toxin-Mediated Interactions}

Of the more than 100,000 identified plant secondary metabolites, many play roles in direct defense against herbivorous insects through anti-nutritive, anti-digestive, or toxic compounds. Many of these defensive chemicals are produced constitutively, regardless of whether a plant is attacked by herbivores; others are often inducible via the JA-based signaling pathway described in Semiochemically Mediated Interactions above (Memelink et al., 2001; Agrawal, 2011; De Geyter et al., 2012). While plant anti-herbivore toxins might be expected to exhibit similar responsiveness as semiochemicals to the damage done by specific herbivores and the presence of their natural enemies, little evidence suggests this is the case. Rather, many secondary compounds are present within only a limited range of plant families (e.g., the glucosinolates are found almost exclusively in plants in the Order Brassicales (Halkier and Gershenzon, 2006), furanocoumarins are primarily associated with the families Apiaceae and Rutaceae (Berenbaum, 1983, 1990)). Specificity of plant defensive responses to different herbivores ('specificity of elicitation' sensu Stout et al., 1998) seems, for the most part, to be quantitative rather than qualitative. For instance, levels of damage caused by different herbivores (Van Zandt and Agrawal, 2004) or variable damage by unparasitized vs. parasitized herbivores that results in differential feeding by herbivores (Ode et al., 2016) may result in the induction of different plant defensive compounds. While some evidence indicates that different herbivores can differentially induce plant defenses (e.g., Stout et al., 1998; Agrawal, 2000b; Poelman et al., 2008), the effects on higher trophic levels are poorly studied.

Unlike indirect defenses (see Semiochemically Mediated Interactions), direct plant defenses typically have negative effects on parasitoid fitness (Ode, 2006, 2013) and occur through one of three, non-mutually exclusive routes. Plant toxins may: (1) reduce host size, having negative consequences for parasitoids feeding on such hosts, (2) pass unmetabolized through the herbivore's midgut into the hemolymph where they are directly encountered by developing parasitoid larvae (Campbell and Duffey, 1979; McGovern et al., 2006; Lampert et al., 2008), or (3) be sequestered for defense against their own natural enemies (Nishida, 2002; Ode, 2006; Lampert et al., 2011a). For example, the catalpa sphinx moth, Ceratomia catalpae (Boisduval) (Lepidoptera: Sphingidae), sequesters the iridoid glycoside catalpol when it feeds on the catalpa plant, Catalpa bignonioides Walter (Lamiales: Bignoniaceae) (Lampert et al., 2010). Interestingly, the parasitoid Cotesia congregata (Say) (Hymenoptera: Braconidae) appears to be little affected by concentrations of catalpol, which also accumulate in the tissues of the parasitoid suggesting the role of this compound as protection against its own hyperparasitoids (Lampert et al., 2011a).

Whether parasitoids are adversely affected by plant toxins depends in large part on the level of host plant specialization of their herbivorous hosts. The diversity of host plants on 
which a given herbivore develops depends, in part, on its ability to metabolize or avoid plant defensive toxins (Schoonhoven et al., 2005). Herbivores feeding on a broader range of host plants typically possess detoxification enzyme systems capable of metabolizing a broad array of plant toxins (Krieger et al., 1971; Li et al., 2004; Ali and Agrawal, 2012). Conversely, herbivores with specialized diets tend to have more efficient detoxification enzymes that metabolize the narrower range of plant toxins to which they are exposed (Wittstock et al., 2004; Mao et al., 2006). Far less documentation exists regarding the consequences for parasitoids of developing in generalist vs. specialist herbivores because few studies have documented the levels of unmetabolized plant toxins in the hemolymph of herbivores with different diet breadths. In one study, significantly more xanthotoxin was passed unmetabolized into the hemolymph of the cabbage looper, Trichoplusia ni (Hübner) (Lepidoptera: Noctuidae), a generalist herbivore, than was passed in the hemolymph of the parsnip specialist Depressaria pastinacella (Geeze) (Lepidoptera: Oecophoridae) (Lampert et al., 2011b). In turn, Copidosoma floridanum Ashmead (Hymenoptera: Encyrtidae) (a parasitoid of T. ni) suffered increased mortality and reduced clutch sizes relative to Copidosoma sosares (Walker) (Hymenoptera: Encyrtidae) (a specialist parasitoid of $D$. pastinacella) even though both herbivore-parasitoid combinations were reared on the same artificial diets (Lampert et al., 2011b). Other studies have documented similar patterns (e.g., Barbosa et al., 1986, 1991). Finally, generalist and specialist herbivores of cruciferous plants are negatively affected by different classes of glucosinolates. Generalist herbivores are typically susceptible to both indole and aliphatic glucosinolates, whereas specialist herbivores are susceptible to just indole glucosinolates (Gols et al., 2008a,b; Müller et al., 2010; Harvey and Gols, 2011). However, some specialists are known to sequester glucosinolates, providing protection against their natural enemies [e.g., the turnip sawfly Athalia rosae (Hymenoptera: Tenthredinidae) (Müller et al., 2002) and the specialist aphids Brevicoryne brassicae (L.) and Lipaphis erysimi Kaltenbach (Hemiptera: Aphididae)] (Francis et al., 2001; Rossiter et al., 2003; Kazana et al., 2007). Interestingly, survivorship and body size of unparasitized T. ni were negatively correlated with concentrations of aliphatic glucosinolates whereas survivorship and clutch sizes of $T$. ni parasitized by $C$. floridanum were negatively affected by concentrations of indole (and not aliphatic) glucosinolates (Ode et al., 2016).

Despite long-running discussions about the potential (in)compatibilities of biological control and breeding programs for plant resistance (e.g., Bergman and Tingey, 1979; van Emden, 1991; Bottrell et al., 1998; Cortesero et al., 2000; Poppy and Sutherland, 2004), surprisingly little is known about the severity of these incompatibilities. This is primarily a reflection of the independent paths that host plant resistance and biological control programs have taken; i.e., IPM is rarely practiced in reality. Part of the difficulty lies in the fact that when crop varieties are bred for insect resistance, rarely do we know the exact mechanism involved. Nonetheless, breeding programs likely select for plant defensive toxins in many cases, which likely mediate resistance. When true, we expect that many of the patterns outlined above will hold. For instance, soybeans, Glycine max (L.) (Fabales: Fabaceae), with the Rag1 gene are resistant to soybean aphid Aphis glycines Matsumura (Hemiptera: Aphididae). Compatibility studies between Rag1 and biological control agents of A. glycines have shown that these agents are less effective (e.g., reduced foraging efficiency and survivorship) on soybean varieties containing the resistant Rag1 gene (Lundgren et al., 2009b; Ghising et al., 2012; Ode and Crompton, 2013).

\section{Case Study: Cotton, Gossypol and Bt Toxins, Herbivores, and Natural Enemies}

Cotton, Gossypium hirsutum L. (Malvales: Malvaceae), the most important plant-based fiber used by humans worldwide, presents an interesting example of the difficulties in breeding for resistance against multiple insect pests. It is consumed by a large number of insect herbivores including the boll weevil, bollworm, pink bollworm, tobacco budworm, armyworms, cotton aphid, whiteflies, Lygus bugs, and thrips (Matthews and Tunstall, 1994; Hagenbucher et al., 2013a). Prior to the introduction of Bacillus thuringiensis $(\mathrm{Bt})$ cotton and more effective IPM approaches, insecticides were the primary means of pest control. An array of morphological (e.g., trichomes) and chemical defenses are produced by cotton and of the chemical defenses, terpenoids (especially gossypol and related compounds) are the best studied. Gossypol, present in leaves and seeds, provides resistance to a broad range of lepidopteran pests (Bottger and Patana, 1966). As it is also toxic to humans, breeding efforts have selected for glandless cultivars that produce low gossypol levels, but these cultivars are particularly susceptible to a range of insect pests (Jenkins et al., 1966). Recent efforts using RNAi to produce low gossypol levels in the seeds while maintaining high levels elsewhere have been successful (reviewed in Hagenbucher et al., 2013a), but gossypol also has negative effects on some natural enemies. For instance, Campoletis sonorensis (Cameron) (Hymenoptera: Ichneumonidae) experiences reduced body size, reduced survivorship, and increased development time when developing on $H$. virescens that had fed on diets high in gossypol (Gunasena et al., 1989), although this negative effect is by no means universal across species (e.g., Sun et al., 2011). Similar to semiochemically induced effects, responses of organisms to different compounds are specific to the exact plant-insect interaction.

The recent focus in cotton breeding for insect herbivore resistance has centered on the development of Bt transgenic lines expressing Cry-endotoxins that confer resistance against lepidopteran herbivores. In particular, adoption of Bt cotton has been credited with the eradication of the pink bollworm Pectinophora gossypiella (Saunders) (Lepidoptera: Gelechiidae) in the southwestern United States (Carriére et al., 2003) and substantial declines of Helicoverpa armigera (Hübner) (Lepidoptera: Noctuidae) in China (Wu et al., 2008). The specificity of Cry toxins against lepidopterans and reduced pesticide use after widespread adoption of $\mathrm{Bt}$ cotton has provided an environment favorable to natural enemies, allowing increased control of a wide variety of cotton pests (Naranjo, 2011; Lu et al., 2012). However, Bt has not been without its downsides as damage by some pests, for example, mirid bugs (Lu et al., 2010), have been 
documented to increase with the widespread use of Bt cotton, presumably because of competitive release from lepidopterans. Another complication involves improved success of the cotton aphid Aphis gossypii Glover (Hemiptera: Aphididae) on Bt cotton. Suppression of feeding by lepidopteran herbivores on Bt cotton reduces induction of key defensive terpenoids, such as gossypol, making these plants much more susceptible to aphids, which do not induce terpenoids (Hagenbucher et al., 2013b). Furthermore, induced terpenoids from non-Bt cotton end up in the hemolymph of the aphids, reducing success of attack by the parasitoid Lysiphlebus testaceipes (Cression) (Hymenoptera: Braconidae) (Hagenbucher et al., 2014b). Reduced parasitism was most likely due to reduced parasitoid acceptance of aphids feeding on lepidopteran-infested non-Bt cotton. Finally, as honeydew is an important source of nutrition for foraging parasitoids, the effect of honeydew from lepidopteran-infested Bt and non-Bt cotton on two important parasitoids of cotton pests, L. testaceipes and the whitefly parasitoid Eretmocerus eremicus Rose and Zolnerowich (Hymenoptera: Aphelinidae) was compared. While gossypol and other terpenoids were significantly higher in the honeydew produced on lepidopteraninfested non-Bt cotton, this did not affect the quality of the honeydew in terms of its effects on parasitoid longevity or fecundity (Hagenbucher et al., 2014a).

\section{Plant Nutrient-Mediated Interactions}

The proteins, sugars, lipids, nucleic acids, vitamins, and minerals contained within plant tissue provide the nutrition necessary for growth, development, and survival of many insects. In turn, the nutrients provided by plants to herbivores affect the nutrients subsequently available to their natural enemies. The presence, quantity, quality, and availability of these nutrients varies significantly between plant species and varieties, and can be affected by season, plant phenology, and other biotic and abiotic conditions (Fox et al., 1990; Roth and Lindroth, 1995; Walde, 1995; Stadler and Mackauer, 1996).

A key indirect interaction between host plant nutrition and natural enemies occurs when herbivore growth and development is delayed by suboptimal plant quality, extending the period of time when herbivores are vulnerable to attack (Moran and Hamilton, 1980; Price et al., 1980; Price, 1986; Loader and Damman, 1991; reviewed in Benrey and Denno, 1997). An example of this "slow-growth-high-mortality" hypothesis was reported for the Mexican bean beetle Epilachna varivestis Mulsant (Coleoptera: Coccinellidae) feeding on soybean. The spined soldier bug, Podisus maculiventris (Say) (Hemiptera: Pentatomidae), was better able to control $E$. varivestis on crop varieties that lowered the herbivore's growth rate (Price et al., 1980), although the exact resistance mechanism was not known. In addition to a longer period of vulnerability, a slow herbivore growth rate can be advantageous if the natural enemy's functional response is stronger when consuming smaller prey, as tends to be the case with predators (Price, 1986). Insect pathogens, in particular, are positively associated with the slow-growthhigh-mortality hypothesis (Schuster et al., 1983; Hamm and Wiseman, 1986). In one case, S. frugiperda feeding on resistant maize plants had reduced growth and vigor, making them more susceptible to infection with nuclear polyhedrosis virus (NPV) (Hamm and Wiseman, 1986). However, the slow-growthhigh-mortality hypothesis does not hold true for all tritrophic interactions. For example, Leather and Walsh (1993) found that pine beauty moth Panolis flammea Denis and Schiffermüller (Lepidoptera: Noctuidae) larvae were not more vulnerable to natural enemies when development was delayed by host plant quality. Some natural enemies, such as parasitoids, may actually be at a disadvantage when their hosts are smaller and/or of lower quality, and smaller hosts may also affect the sex ratio and fecundity of parasitoid populations (Kuo, 1986). It is therefore important to examine whether the presence of smaller and lower quality hosts due to suboptimal plant nutrition has a large enough impact on parasitoids as to affect their ability to suppress pest populations.

Many natural enemies also engage in omnivory, supplementing their prey-based diet with plant-provided resources (reviewed in Lundgren, 2009), particularly during periods when prey abundance is low. This can allow for more stable interactions between predators and prey (Agrawal, 2000a) and may facilitate early season colonization of crop fields and better pest suppression due to this "lying in wait" of natural enemies prior to arrival of the pest species (Settle et al., 1996; Eubanks and Denno, 1999; Athey et al., 2016). Therefore, good quality plant hosts in the case of omnivorous natural enemies is essential for a positive relationship between plant and biocontrol. Plants expressing herbivore defense traits can have direct impacts on facultatively phytophagous predators but the literature is lacking in how these interactions will impact the compatibility of host plant resistance with biological control (Lundgren, 2009).

Some insects are truly omnivorous, having a flexible trophic strategy that allows them to utilize either plant or prey resources, with the potential to inflict crop damage if engaging in phytophagy. For example, the western flower thrips Frankliniella occidentalis (Pergande) (Thysanoptera: Thripidae) feeds on plant material and arthropod prey, leading to its role as both a serious pest (Grazia-Tommasini, 1995; Kirk and Terry, 2003) and a biological control agent (Trichilo and Leigh, 1986; Wilson et al., 1996; Agrawal and Karban, 1997; Milne and Walter, 1997). Furthermore, Agrawal et al. (1999) revealed that the presence of prey [eggs of the Pacific spider mite Tetranychus pacificus McGregor (Thysanoptera: Tetranychidae)] reduced feeding by F. occidentalis on cotton by nearly $50 \%$. However, when cotton plants were first exposed to feeding pressure by spider mites, eliciting systemically induced plant defenses that lower host plant quality, herbivory by F. occidentalis was reduced (Agrawal et al., 1999). When both induced host plant defenses and T. pacificus egg prey were available, feeding preference shifted to consume half the amount of cotton tissue and twice the number of prey (Agrawal et al., 1999). Thus, host plant quality and prey availability are important factors for arthropods with omnivorous trophic tendencies.

Extrafloral nectaries (EFN) are a plant-provided resource that deserve additional attention because of their role in natural enemy nutrition. It is hypothesized that the main function of extrafloral nectar is to recruit predators and parasitoids for the protection of the plant against herbivores, an example of 
indirect host plant resistance (Bentley, 1977; Koptur, 1992; Turlings and Wäckers, 2004). Some EFN emit olfactory signals that are attractive to natural enemies, such as parasitoids (Lewis and Takasu, 1990; Stapel et al., 1997). By providing nutritional resources, the presence of EFN can lead to enhanced herbivore suppression by arthropod natural enemies, such as ants (Bentley, 1977; Smiley, 1986), spiders (Ruhren and Handel, 1999), predatory mites (Bakker and Klein, 1992), coccinellids (Stephenson, 1982) and parasitoids (Lindgren and Lukefahr, 1977). Interestingly, some plants produce a consistent low level of EFN, but increase production in response to herbivory; in this manner, extrafloral nectaries can be considered both constitutive and inducible indirect host plant resistance (Wäckers et al., 2001; Wäckers and Bonifay, 2004; Lundgren, 2009; Heil, 2015). The applied implications of EFN production by crop plants is examined in the case study with cotton below.

\section{Case Study: Extrafloral Nectar-Producing Cotton, Its Herbivores, and Natural Enemies}

The ability of extrafloral nectar to attract natural enemies for biological control of cotton pests has long been exploited. Cook $(1904,1905)$ reported on the practice of indigenous farmers in Guatemala, who purposely cultivated cotton near nests of the tropical ant Ectatomma tuberculatum (Olivier) (Hymenoptera: Formicidae). In addition to feeding on EFN, these ants attacked boll weevil Anthonomus grandis Boheman (Coleoptera: Curculionidae) adults. Subsequently, plant breeding efforts in the mid 1900's attempted to develop cotton varieties that lacked EFN, due to the observation that both natural enemies and some lepidopteran pests, such as $P$. gossypiella, benefitted from cotton nectaries (Lukefahr and Griffin, 1956; Lukefahr and Rhyne, 1960; Bentley, 1983). However, the benefit of a modest reduction in lepidopteran pests was outweighed by the disadvantage of reduced natural enemy populations, although this conclusion was doubted at the time (Rogers, 1985; Schuster and Calderon, 1986). The population of natural enemies in "nectarless" cotton varieties was up to $35 \%$ lower than EFN-producing cotton and the presence of EFN in cotton had positive impacts on the attraction, retention, and efficiency of many predators, including chrysopids, anthocorids, and coccinellids (Schuster et al., 1976). Similarly, the parasitoid Microplitis croceipes (Cresson) (Hymenoptera: Braconidae), which attacks larvae of the bollworm $H$. zea, is stimulated to stay longer and attack a greater number of hosts in the presence of nectar (Stapel et al., 1997). Many other examples exist in the literature, providing clear evidence for widespread benefits of EFN to parasitoids (e.g., Treacy et al., 1987). Another functional group of natural enemies, cursorial wandering spiders such as Cheiracanthium inclusum (Hentz) (Araneae: Miturgidae) and Hibana futilis (Banks) (Araneae: Anyphaenidae), are important nocturnal predators of lepidopterous pest eggs in cotton (Pfannenstiel, 2008) and consume EFN in the field (Taylor and Pfannenstiel, 2008). Furthermore, Hibana futilis responds to olfactory cues from extrafloral nectar and engages in restricted area searching following contact with nectar (Patt and Pfannenstiel, 2008, 2009) and profound improvements of survival are evident when provided EFN in the diet (Taylor and Pfannenstiel, 2009; Pfannenstiel and Patt, 2012).

The majority of modern cotton varieties now produce EFN, but past breeding efforts illustrate the difficulty in managing plant traits affecting both pests and natural enemies. Rogers (1985) recommended that for the case of nectar-producing cotton, varieties should be developed that produce nectar that is palatable to beneficial species, but not pests. However, the feasibility of this suggestion has not been explored. Recommendations to improve the recruitment of natural enemies to cotton fields include selecting for varieties with enhanced nectar production. For example, most cotton leaves bear a single nectary, but some have three (Cortesero et al., 2000) and a breeding challenge is whether cotton varieties can be developed with a greater number of nectaries. It is evident that plant nutrients are critically important to a diverse array of natural enemies across multiple functional groups. Integration of this resource into biological control programs through selective enhancement or provisioning of additional nectar sources can assist when developing sustainable solutions to pest management. Clearly, challenges exist when selectively breeding for plant defense traits (described here and in other sections), but careful consideration of their integration with biological control can provide synergistic levels of pest control.

\section{Physically Mediated Interactions}

Just as some tritrophic interactions involve both semiochemicals and toxins, physically mediated interactions do not always function alone. For example, substances such as resin or latex physically limit herbivores by trapping or immobilizing them, while simultaneously delivering various toxins (Konno, 2011), and glandular trichomes release sticky and toxic compounds serving as a physical and chemical defense against herbivores (Levin, 1973; Southwood, 1986; Cortesero et al., 2000).

Plant architecture affects the dispersion of herbivores on a host plant, which may in turn affect searching behavior and hostfinding abilities of natural enemies. For example, the leaves of winter wheat varieties developed for resistance to Russian wheat aphid Diuraphis noxia (Kurdjumov) (Hemiptera: Aphididae) remain flat, compared to susceptible varieties whose leaves furl in response to aphid feeding (Hawley et al., 2003), exposing aphids to disturbances such as wind, rain, and predators inducing them to fall from the plant (von Berg et al., 2008). Characteristics that affect falling behavior of herbivores can affect predation rates as they experience vulnerability to ground-dwelling predators and may also face additional challenges from natural enemies as they attempt to recolonize the plant (Sunderland et al., 1986; Winder, 1990; Winder et al., 1994).

The size and morphology of certain plant structures that confer resistance to herbivores can affect biological control by altering where pests feed, how long they are exposed and how apparent or accessible the pests are to natural enemies, particularly if plant morphology can delay internally feeding pests from entering the plant's tissues. An example would be husk tightness and length in sweet corn plants conferring resistance to H. zea larvae attempting to enter the ear and feed on developing kernels (Cameron and Anderson, 1966; Wiseman and Davis, 1990). Plant structures may also act to hide the herbivore from its 
natural enemies. For example, open-leaf brassica varieties, such as Brussels sprouts, have higher parasitism on $P$. rapae compared to heading varieties, such as cabbage, due to larvae being able to feed in leaf folds protected from parasitoids (Pimentel, 1961). Furthermore, the size of plant structures impacts the ability of parasitoids to oviposit in pests, particularly if larger fruits allow pests to feed deeper than the parasitoid's ovipositor can reach, creating "enemy-free space" and potentially facilitating host switching by pests (Bush, 1974; Price et al., 1980; Jeffries and Lawton, 1984; Bernays and Graham, 1988).

The plant surface is a complex microenvironment playing a critical role in insect-plant interactions, impacting insect behavior (such as attraction, retention, and host choice), feeding (such as attachment and accessibility of nutrients), and dispersal (by impeding insect movement) (Chapman, 1977; Southwood, 1986). Leaf surface structures that defend the plant from herbivores, such as leaf toughness, cuticle thickness, epicuticular waxes, trichomes and spines, can have direct and indirect effects on natural enemies. An indirect effect can occur if physical defense traits, such as leaf toughness, delay the development of herbivores. The extended period of vulnerability to natural enemies can thereby enhance biological control (slow-growth-high-mortality hypothesis, see Plant NutrientMediated Interactions). A common example of direct effects is when trichomes are physically disruptive to natural enemy movement. In general, trichomes have more harmful than beneficial effects on predators, although most of these effects are sublethal (Riddick and Simmons, 2014a,b). The functional response or attack rate of predators and parasitoids is typically lower when their prey or hosts are found on plants with greater trichome density (e.g., Krips et al., 1999; Kumar et al., 1999; De Clercq et al., 2000; Stavrinides and Skirvin, 2003; Madadi et al., 2007; Jalalizand et al., 2012), although the opposite has been found as well (Koveos and Broufas, 2000). These interactions have significant implications for pest management; for example, biological control is possible on glabrous cucumber varieties, but is seriously hindered on those with dense trichomes due to the reduction in searching efficiency by the parasitoid Encarsia formosa Gahan (Hymenoptera: Aphelinidae) attacking greenhouse whiteflies Trialeurodes vaporariorum Westwood (Hemiptera: Aleyrodidae) (Hulspas-Jordaan and van Lenteren, 1978). Clusters of trichomes on the underside of plant leaves can form domatia, commonly used by predatory arthropods for shelter (O'Dowd and Willson, 1991; Walter, 1996; Agrawal and Karban, 1997); the positive impact of domatia on biological control has been well-documented for predatory phytoseiid mites (reviewed in Schmidt, 2014). In general, arthropods need to be either quite large (Rabb and Bradley, 1968; Obrycki and Tauber, 1984) or very small (Krips et al., 1999) to move along a leaf surface unimpeded by physical plant defense structures. The effect of trichome density on natural enemy movement can be a function of the relationship between natural enemy size and trichome spacing (Buitenhuis et al., 2014).

This myriad of physical plant traits clearly has an important effect on the feeding efficiency of herbivores. However, integration of plant physical traits with biological control is a complex issue with characteristics hindering herbivore damage also affecting (positively and negatively) the ability of natural enemies to attack pest species. This trade-off is evident in many examples of physically mediated interactions. In addition to trichomes, another plant surface characteristic that can impact natural enemies is the presence and composition of epicuticular waxes, which will be discussed in the following section.

\section{Case Study: Plant Epicuticular Waxes, the Diamondback Moth, and Its Predators}

Plant epicuticular waxes primarily serve to control water, gas and solute exchange (Riederer and Müller, 2006). In addition, these waxes mediate other ecological functions including host plant resistance against pathogens (Reina-Pinto and Yephremov, 2009) and herbivores (Eigenbrode et al., 1991b; Müller, 2008). The interactions between B. oleracea (cabbage, broccoli, cauliflower, kale, and others), Plutella xylostella (L.) (Lepidoptera: Plutellidae), and its predators highlight the interface between plant waxes and herbivore resistance. Gene mutations yield $B$. oleracea cultivars with altered chemical structures and different crystallization patterns of epicuticular lipids (Macey and Barber, 1970; Netting et al., 1972; Baker, 1974). As a consequence, mutants usually have decreased epicuticular waxes and produce a "glossy" phenotype instead of their normal wax "glaucous" phenotype (Eigenbrode and Espelie, 1995). Although information is limited (Verkerk and Wright, 1996), evidence suggests that glossy plants exhibit resistance against neonate P. xylostella larvae (Lin et al., 1983; Eigenbrode and Shelton, 1990; Eigenbrode et al., 1991a) and that physical and chemical differences influence neonate behavior (Eigenbrode et al., 1991b). Neonates on glossy varieties disperse further and faster, spending less time palpating, biting, mining, and spinning silk (Eigenbrode and Shelton, 1990; Eigenbrode et al., 1991a). This non-preference behavior causes a lack of establishment, reduced feeding and increased larval mortality (Eigenbrode and Shelton, 1990; Eigenbrode et al., 1991a).

Host plant resistance conferred by the glossy phenotype is also enhanced by predators. Field studies revealed that green lacewing Chrysoperla carnea (Stephens) (Neuroptera: Chrysopidae), insidious flower bug Orius insidiosus (Say) (Hemiptera: Anthocoridae), and convergent lady beetle Hippodamia convergens Guérin-Méneville (Coleoptera: Coccinellidae), all generalist predators, significantly increased P. xylostella larval mortality in glossy, but not normal wax, varieties (Eigenbrode et al., 1995). The reduction in mining behavior renders the larvae more exposed to predators (Eigenbrode et al., 1995). Predators also walked faster, spent more time walking, and covered more leaf area on glossy leaves compared to normal wax varieties (Eigenbrode et al., 1996). Increased mobility was attributed to increased traction/adhesion of predators on glossy vs. normal wax plants. The crystallization and composition of natural waxes have an impact on how natural enemies, such as $H$. convergens and Chrysoperla plorabunda (Fitch) (Neuroptera: Chrysopidae) attach to the leaf surface, thereby affecting their ability to exert biological control (Eigenbrode et al., 1999; Eigenbrode and Jetter, 2002).

In summary, this system has multiple pest suppression factors working together. Plutella xylostella neonates are less likely 
to accept glossy varieties, which increases their mortality and vulnerability to predation (via decreased mining behavior). Predators on glossy varieties have a greater ability to walk and hence, locate and attack prey, due to increased adhesion to the surface of leaves. Altogether, host plant resistance for P. xylostella in glossy varieties increases biological control by natural enemies, and hence overall suppression of this key pest of Brassica plants.

\section{Mechanisms of Plant Trait-Mediated Interactions: Summary}

Plant traits have a profound (and often complex) array of impacts on herbivores and natural enemies. The examples cited within each section above for semiochemically, plant toxin-, plant nutrient-, and physically mediated interactions show the diversity and gradient of interactions occurring between natural enemies and HPR and how these can interact synergistically or antagonistically to suppress the target pest. For instance, semiochemically mediated traits serve as indirect plant defenses by impacting signaling pathways and attraction/repellency between the members of tritrophic interactions. Conversely, plant toxins act as direct defense against herbivores and this in turn can alter host suitability for natural enemies. Insect host/prey vulnerability via the slow-growth-high-mortality hypothesis can be mediated by plant nutrition. Plant-provided nutritional resources can also be linked to the success of natural enemies due to omnivory by predators and/or parasitoids. Moreover, physically mediated traits are known to function together with other traits to deter herbivory, but physical plant defenses are also responsible for increasing or decreasing herbivores' vulnerability to natural enemies and trichomes can have direct negative impacts on biological control by decreasing natural enemy search efficiency. Manipulation of plant traits through plant breeding or bioengineering, as well as knowledge of the ecology and biology of herbivores and natural enemies, can work together to aid crop protection. In the last two decades, another control tactic, Bt, has become a staple of the agricultural landscape throughout much of the world (although notably less so in Europe). This technology will be discussed below given its importance in pest control programs throughout the world.

\section{GENETICALLY MODIFIED CROPS AND INTERACTIONS WITH BIOLOGICAL CONTROL}

Transgenic genetically modified (GM) crops have been engineered to incorporate genes derived from another species that confer nutritional or agronomic benefits, such as resistance to insect pests, viruses, herbicides, or protection from environmental conditions (e.g., low water availability). Among insect-resistant GM crops, Bacillus thuringiensis (Bt) crops are the most common and express insecticidal proteins derived from a naturally occurring soil bacterium. The insecticidal mode of action occurs when Bt toxins bind to receptors on the midgut lining of susceptible insects, causing lysis of epithelial cells on the gut wall, perforations in the midgut lining, cessation of feeding, and death by septicemia. Bt toxins target a narrow spectrum of pest insects that possess specific physiological traits (i.e., gut $\mathrm{pH}$ and toxin receptor sites in the midgut), and thus pose less direct toxicity risk to non-target species than broad-spectrum insecticides (Marvier et al., 2007; Wolfenbarger et al., 2008; Naranjo, 2009; Duan et al., 2010; Peterson et al., 2011). Commercialized Bt crops include maize, cotton, and soybeans that are protected against a suite of coleopteran and lepidopteran pests. The planting of Bt crops has increased dramatically since their introduction in the mid-1990's; for example, in the United States, the percentage of Bt maize was only $1 \%$ of the total crop grown in 1996 but $81 \%$ of all maize grown in 2015 (United States Department of Agriculture National Agricultural Statistics Service, 2015). The ecological interactions between insect-resistant GM crops and biological control are complex and have been addressed in numerous comprehensive reviews (e.g., Obrycki et al., 2004; Lundgren et al., 2009a; Hilbeck and Otto, 2015). Two major categories for how GM crops influence biological control, proposed by Lundgren et al. (2009a), are discussed below: (1) toxicity-based pathways, including natural enemy consumption of toxic plant or prey foods; and (2) crop-induced changes to the environment, including unintended alterations to the crop plant and a decrease in prey quality and/or density that alter functional and numerical responses as well as the community ecology of natural enemies.

Many natural enemies consume plant-provided non-prey foods (see Plant Nutrient-Mediated Interactions) and when these plant-provided resources are GM crops, they are likely to contain Bt toxins. The expression of transgenic proteins is influenced by many biotic and abiotic factors, including environment, geography, crop phenology and genetics, and the specific transgenic event and protein expressed (Fearing et al., 1997; Duan et al., 2002; Grossi-de-Sa et al., 2006; Obrist et al., 2006a; Lundgren et al., 2009a). Most Bt crops employ a constitutive promoter that expresses Bt proteins throughout the life of the plant in nearly all tissues. Natural enemies that engage in facultative phytophagy of these plants are therefore likely to be exposed to the Bt toxins. Despite this exposure, laboratory feeding assays and field studies do not report negative impacts (Pilcher et al., 1997; Armer et al., 2000; Lundgren and Wiedenmann, 2002; Geng et al., 2006; Ludy and Lang, 2006; Obrist et al., 2006b; Torres et al., 2006; Li et al., 2008), most likely due to the high specificity of Bt proteins against target pests and the lack of necessary physiological conditions in non-target arthropods. It is therefore unlikely this pathway has a significant impact on biological control in transgenic crops.

Natural enemies may be exposed to Bt toxins by consuming or parasitizing prey/hosts that have fed on GM crops, a pathway similar to plant toxin-mediated interactions (see Plant ToxinMediated Interactions). One factor mitigating the exposure of natural enemies is that for crop pests that are highly susceptible to Bt toxins, ingestion of a very small amount of toxin elicits lethal effects. Exposure to natural enemies can be greater if the herbivore consuming a GM crop plant is only partially susceptible to the toxin and therefore consumes a greater quantity of plant tissue. Many herbivores do contain transgenic toxins 
(e.g., Harwood et al., 2005; Meissle et al., 2005; Obrist et al., 2005, 2006b; Peterson et al., 2016), but accumulation in higher trophic levels is uncommon (Dutton et al., 2002; Obrist et al., 2006a; Paula and Andow, 2016). While tritrophic transfer of Bt proteins has been documented, it is at low levels (e.g., Harwood et al., 2005, 2007; Meissle et al., 2005; Zwahlen and Andow, 2005; Obrist et al., 2006a; Wei et al., 2008; Chen et al., 2009; Meissle and Romeis, 2009; Peterson et al., 2009, 2016; Tian et al., 2010; Han et al., 2015). Early studies reported that some predators had negative sub-lethal effects from exposure to Bt-containing prey (Hilbeck et al., 1998a,b; Ponsard et al., 2002) but it was subsequently revealed that this was the result of reduced prey quality rather than direct exposure to $\mathrm{Bt}$ toxins (Romeis et al., 2004; Torres and Ruberson, 2006).

The most likely action by which GM crops could influence natural enemy fitness and fecundity is through a reduction in prey quality and/or prey density. Numerous studies have shown that consumption of $\mathrm{Bt}$-containing plant tissue negatively affects the growth and development of herbivorous species, thereby impacting their natural enemies (e.g., Lövei and Arpaia, 2005; Hilbeck and Schmidt, 2006; Romeis et al., 2006; Lawo et al., 2010; Garcia et al., 2012; Tian et al., 2014; Han et al., 2015). For example, Hilbeck et al. (1998a) reported that the generalist predator C. carnea experienced reduced larval survival and longer development time when fed a diet of European corn borer (ECB), Ostrinia nubilalis (Hübner) (Lepidoptera: Crambidae), that had consumed Bt corn. However, generalist predators are capable of preferential feeding on healthy prey (Ferry et al., 2006) and are able to shift their dietary preferences to consume the mixture of nutrients required for optimal fitness (Mayntz et al., 2005; Raubenheimer et al., 2007; Marques et al., 2015). Therefore, generalist predators may be able to compensate for reduced quality of select prey due to Bt toxin consumption, having a negligible impact on biological control. For entomopathogens, species that are specialists of Bt-targeted pests are likely to see population reductions, whereas generalists will continue to persist in Bt crop fields (Obrycki et al., 2004). Parasitoids often do not have the flexibility to select hosts unaffected by Bt toxins and are therefore more likely to be adversely affected (Bernal et al., 2004; Marvier et al., 2007; Wolfenbarger et al., 2008; Bernal, 2010). Specialist parasitoid populations are reduced due to a lack of suitable hosts and may also suffer direct mortality if they are developing inside of a host that suffers mortality due to ingestion of Bt toxins (Agrawal, 2000a). For hosts that are only partially susceptible to Bt toxins, reduced host quality can result in sublethal effects on parasitoids (e.g., Bernal et al., 2002; Baur and Boethel, 2003; Vojtech et al., 2005; RamirezRomero et al., 2007; Walker et al., 2007), but host-mediated impacts of Bt crops on parasitoids are not universal and vary depending on the plant, host, and parasitoid. For example, the soybean looper Chrysodeixis includens (Walker) (Lepidoptera: Noctuidae) is moderately susceptible to the Bt toxins expressed in transgenic cotton and exhibits slower development time and lower prepupal weight (Baur and Boethel, 2003). Parasitism by Cotesia marginiventris (Cresson) (Hymenoptera: Braconidae) on these hosts results in longer larval development time, reduced adult longevity, and reduced egg production. However, when
C. floridanum parasitizes loopers that have fed on Bt cotton, wasp pupal development time and adult longevity are unaffected, but fewer adults are produced per host (Baur and Boethel, 2003), revealing the difference in effects between species. In addition to development time, natural enemy size can be reduced if feeding on lower quality prey or hosts; smaller size in insects can result in reduced fecundity and dispersal capacity (Honěk, 1993; Kazmer and Luck, 1995), further delaying natural enemy population growth (Lundgren et al., 2009a).

The majority of interactions discussed above operate at the scale of a single crop field or smaller. However, some effects of the proliferation of GM crops are observed at the landscape or community scale. For example, Bt maize has been associated with area wide suppression of ECB in the midwestern United States (Hutchison et al., 2010). Despite reduced ECB populations that confer economic benefits to growers planting non-Bt maize, management of this pest is still critical for seed corn, popcorn, and other crops not protected by Bt toxins. Therefore, suppression of ECB due to biological control by natural enemies such as the specialist parasitoid Macrocentrus grandii (Goidanich) (Hymenoptera: Braconidae) and the entomopathogenic microsporidian Nosema pyrausta (Paillot) (Microsporidia: Nosematidae) is a valuable service. Despite the large reduction in ECB populations, infection dynamics of $N$. pyrausta have not significantly changed (Lewis et al., 2009), although parasitism rates by $M$. grandii were lowest when ECB hosts were found in small aggregations (White and Andow, 2005). Therefore, the area wide suppression of Bttargeted prey or hosts does not always affect the interactions of pests with their natural enemies.

In addition to transgenic Bt crops, other herbicide-resistant and insecticidal GM crops are commercially available or under review by governmental agencies. The adoption of herbicidetolerant crops that confer resistance to herbicides such as glyphosate, glufosinate, and 2,4-Dichlorophenoxyacetic acid (2,4D) has been rapid. In the United States, $89 \%$ of corn and upland cotton and $94 \%$ of soybeans planted in 2015 had GM herbicidetolerance traits (United States Department of Agriculture National Agricultural Statistics Service, 2015). Furthermore, herbicide-tolerant canola, alfalfa, and sugar beets are currently being grown in the United States, albeit in reduced frequency. This adoption has led to changes in the agricultural landscape, including reduced within-field plant diversity (Heard et al., 2005; Culpepper, 2006; Pleasants and Oberhauser, 2013), potentially affecting natural enemies and conservation biological control. The potential consequence of GM herbicide-tolerant crops on biological control is addressed in detail by Lundgren et al. (2009a). Transgenic insecticidal traits other than Bt have been studied; for example, potatoes, rice, maize, sugarcane, wheat, and other crops have been engineered to express snowdrop lectin GNA, a protein produced by the common snowdrop plant Galanthus nivalis (Asparagales: Amaryllidaceae) that expresses anti-hemipteran properties (Gatehouse et al., 1996; Sudhakar et al., 1998; Wang et al., 2005; Zhangsun et al., 2007; Duan et al., 2015). However, negative impacts of snowdrop lectin on natural enemies have been reported (Birch et al., 1999; Sétamou et al., 2002a,b,c; Horgervorst et al., 2006; Li and Romeis, 2009). The 
next generation of transgenic insecticidal crops in the commercial pipeline utilizes RNA interference (RNAi), where small double stranded RNA molecules expressed in the plant selectively silence targeted genes in herbivores that feed on the plant (Siomi and Siomi, 2009). For the western corn rootworm (WCR), silencing the $D v S n f 7$ gene using genetically modified RNAi maize induces mortality of this pest (Baum et al., 2007; Bolognesi et al., 2012) but the interactions between RNAi crops and biological control are not fully understood. While the reported spectrum of insecticidal activity of DvSnf7 RNAi is limited to a subset of species related to the WCR (Bachman et al., 2013), further risk-assessment is clearly required. The potential hazards of GM RNAi crops to natural enemies include off-target gene silencing, silencing of the targeted gene in non-target organisms, immune stimulation, and saturation of the RNAi machinery; however, these interactions may be highly complex and difficult to predict (see reviews by Lundgren and Duan, 2013; Casacuberta et al., 2015; Roberts et al., 2015). Consequently, understanding the potential effect that GM crops have on natural enemy-pest dynamics will allow for better integration of this technology with biological control services. Genetically engineered biotech crops undoubtedly afford significant levels of pest suppression; research on the compatibility of this approach with biological control is critical to address the long-term integration of both approaches.

\section{DISCUSSION}

\section{Top-Down vs. Bottom-Up Control of Herbivorous Populations}

As emphasized throughout this review, IPM ideally integrates a range of approaches to reduce damage caused by insect pests. Two of these approaches, HPR and biological control, are essentially forms of bottom-up and top-down control of herbivore populations. Whether breeding for increased plant resistance and the use of biological control are compatible and complementary approaches depends, in large part, on the mechanisms involved in HPR and the effects they have on biological control agents. Plant breeding for increased toxicity to herbivores will likely have negative effects on any biological control agents of these herbivores, whether due to direct ingestion of plant toxins or the effects of reduced host or prey size. In this respect, the array of interactions described in the Plant ToxinMediated Interactions and Plant Nutrient-Mediated Interactions sections are expected to apply here. An increasing number of studies have demonstrated that HPR has negative consequences for biological control agents through reduced body size or survivorship of individual natural enemies, raising the concern that such approaches are incompatible. Perhaps true in some circumstances, this is not always the case. Even if these control tactics negatively interact, the net effect in suppressing pest populations may be greater than use of either strategy alone. While rarely done, studies evaluating the joint effects of HPR and biological control efforts on pest population dynamics are essential to design effective and sustainable IPM strategies to minimize pest damage. Conversely, efforts to increase HPR by selecting for varieties that increase production of volatiles attractive to biological control agents are clearly compatible with biological control approaches. These interactions have been discussed in the Semiochemically Mediated Interactions and Case study: Maize Volatiles, Western Corn Rootworm, and Entomopathogenic Nematodes sections. Too often, however, little is known about the mechanisms underlying plant resistance to herbivory.

In turn, parasitoids can reduce herbivore pressure allowing for increased plant yields. Parasitoids, especially solitary species, can reduce damage done by herbivores, resulting in direct yield benefits to the plant; even gregarious parasitoids, which often induce increased feeding by individual herbivores, can reduce long-term population sizes of herbivores. Indeed, the widespread success of many insect biological control programs speaks to the ability of parasitoids (and predators) to have positive effects on plant production and yield. An underappreciated facet of this interaction between parasitoids and plant fitness/yield is the potential for parasitoids to reduce the likelihood of evolution of herbivore resistance to plant resistance traits. This is discussed further in section "Biological Control Can Reduce the Likelihood of Resistance Evolution.”

\section{Considerations for the Use of Volatiles to Recruit Biological Control Agents}

Most studies involving HIPVs are undertaken in laboratory and greenhouse settings, with fewer studies conducted on the efficacy of HIPVs as host-plant resistance mechanisms in cropping systems at the field scale (Orre et al., 2010; Simpson et al., 2011a,b). Our understanding of arthropod responses to chemical compounds is still evolving, but efforts in developing HIPV strategies for crops are already in place via baiting/lures (Kaplan, 2012) or via bioengineering (Degenhardt et al., 2003, 2009). However, efforts to increase natural enemy efficacy by increasing plant attractiveness via HIPVs cannot ignore potential side effects. Extensive reviews of the challenges and the future of HIPV use in pest management have been published (Dicke, 2009, 2015; Alba et al., 2012; Kaplan, 2012; Heil, 2014) and there are many unknown factors and risks associated with the use of HIPV-based pest management tactics. Cropping systems are often considered low-diversity environments because of monocultural practices but in reality there are a multitude of organisms in any given field emitting and receiving chemical cues. We know that HIPVs targeted to attract natural enemies also attract herbivores, plant parasites, and members of the fourth trophic level. Releasing HIPV technology without examining the ecological factors present may render the technology ineffective. Several studies have shown that application of synthetic elicitors such as methyl jasmonate (MeJA) to induce elevated plant volatile production can also attract herbivores (Ballhorn et al., 2013) as well as hyperparasitoids (Kaplan, 2012; Heil, 2014), both outcomes that would be counterproductive to the potential for increased rates of parasitism by primary parasitoids. Additional spatio-temporal considerations must be understood to apply this technology in a large field setting. Moreover, it is unclear how the intentional use of HIPV technology impacts the net-efficiency of the HIPV-emitting crop. For example, the use of synthetic green 
leaf volatiles and MeJA to induce increased HIPV production in field grown maize did not result in increased parasitism rates by parasitoids of S. frugiperda (von Mérey et al., 2011, 2012). An essential question that needs additional exploration is whether an increase in biological control due to HIPV-emission will equate to increased crop yields.

\section{Biological Control Can Reduce the Likelihood of Resistance Evolution}

Pesticide resistance is listed as the third most serious threat to global agriculture (behind soil erosion and water pollution) (Pimentel, 2005). Resistance is a pest population's decreased response to a pesticide or control agent (including plant defense traits) as a result of previous exposure (McKenzie, 1996) and over 540 arthropod species have developed resistance to at least one pesticide (Arthropod Pesticide Resistance Database, 2016). The evolution of resistance to GM crops is of particular concern. For example, the WCR developed resistance to Cry3Bb1 Bt proteins with cross-resistance to $\mathrm{mCry} 3 \mathrm{~A}$ within 8 years of commercial release in the U.S. (Gassmann et al., 2011; Wangila et al., 2015). The impacts of resistance are often severe and far-reaching: they can lead to economic losses and increased pesticide usage. Delaying or preventing adaptation to pesticides, insecticidal GM crops and host plant defense traits can be achieved through the adoption of an integrated resistance management plan, and biological control can play a large role in these efforts. The impact of biological control on the rate of evolution of pest resistance is dependent upon whether natural enemies disproportionately attack resistant prey/hosts (thereby slowing resistance evolution) or susceptible prey/hosts (thereby accelerating resistance evolution) (Gould et al., 1991). In a high-dose/refuge strategy, such as that used for Bt crops, susceptible pests developing in refuges are frequently found at higher densities than resistant pests feeding on highdose plants. Therefore, if natural enemies preferentially attack hosts found at higher densities (positive density-dependent mortality), the rate of resistance evolution will be faster than if natural enemies prefer less dense hosts (inverse densitydependent mortality) or are unaffected by host density (densityindependent mortality) (Heimpel et al., 2005). For example, Coleomegilla maculata De Geer (Coleoptera: Coccinellidae) exhibits inverse density-dependent predation on the egg masses of the Colorado potato beetle Leptinotarsa decemlineata Say (Coleoptera: Chrysomelidae), decreasing the rate at which this pest develops resistance to Bt potatoes (Arpaia et al., 1997). However, the introduction of alternative prey can alter feeding patterns of this generalist predator, thereby affecting its influence on resistance evolution (Mallampalli et al., 2005).

Natural enemies can enhance resistance management for plant defense traits by inflicting mortality on those pests that have developed resistance (Liu et al., 2014). In oilseed rape Brassica napus L. (Brassicales: Brassicaceae) expressing Bt toxins, for example, the parasitoid Cotesia vestalis (Halliday) (Hymenoptera: Braconidae) dies with their host if developing inside a Btsusceptible $P$. xylostella larva, but does not suffer negative effects when parasitizing Bt-resistant caterpillars (Schuler et al., 1999).
Susceptible P. xylostella are killed within 5 days of feeding on Bt plants and consumption of Bt leaves is significantly reduced for susceptible larvae than resistant larvae. Consequently, the parasitoid C. plutellae is more attracted to Bt-resistant hosts, as plants with greater feeding damage release more HIPVs, which are attractive to the parasitoid (Schuler et al., 1999). Additionally, natural enemies can slow the evolution of resistance if they increase the fitness costs associated with resistance to crop traits (Raymond et al., 2007) but alternatively may amplify selection for resistance if they attack susceptible prey or hosts more frequently (Gould et al., 1991). For example, susceptible H. virescens feeding on Bt tobacco Nicotiana tabacum L. (Solanales: Solanaceae) took longer to develop, exposing them to greater parasitism by Campoletis sonorensis, and had higher movement rates, increasing risk of infection by the entomopathogenic fungus Nomuraea rileyi (Farlow) Samson (Johnson and Gould, 1992; Johnson et al., 1997a,b).

As described, biological control can influence the rate of resistance evolution via top-down influence. However, the manner in which host plant resistance traits are implemented can also have an effect on the evolution of resistance through bottom-up selection. The durability of plant resistance traits is affected by a multitude of factors that influence selection pressure on herbivorous pests, such as planting of a monoculture of resistant plants vs. mixtures or refuges of non-resistant plants, the mechanism and efficacy of the resistance traits, and the use of pyramiding multiple resistance traits (Stout, 2013). To achieve the greatest durability of plant defense traits, and therefore a more stable and sustainable pest management strategy, both top-down and bottom-up methods for delaying evolution of resistance by arthropod pests should be employed.

\section{How Can We Integrate Host Plant Resistance and Biological Control?}

Historically, developers of HPR and biological control programs have worked independently, seeking to find "single-solution approaches to pest problems" (Thomas and Waage, 1996). Communication between such disparate groups such as plant breeders and natural enemy ecologists may not be inherently high. In reality, there are at least four distinct groups that should come together to better integrate plant defense traits and biological control: (1) HPR researchers (including plant breeders), (2) biological control researchers, (3) ecologists studying community and tritrophic interactions, and (4) extension professionals who are implementing IPM programs and working directly with producers and their advisors (Thomas and Waage, 1996). How can these fields and groups be brought together? Currently, plant breeding for HPR includes the selection of plant traits with the goal of enhancing direct defenses against herbivorous pests, with little consideration for enhancing plant traits that could improve indirect defenses through the action of natural enemies against pests (Cortesero et al., 2000). Evaluating the impacts of plant resistance characteristics on common natural enemies in the assessment of plant varieties during breeding for HPR would aid in bringing these two methods together. Additionally, fundamental 
ecological literature and applied host plant resistance literature have suffered from a lack of integration, an observation that has persisted for nearly 30 years (Kogan, 1986; Stout, 2013). An adherence by the host plant resistance community to the three traditional categories of resistance: antibiosis, antixenosis and tolerance (Painter, 1951) may also account for the lack of consideration of the third trophic level (Stout, 2013). Induced, indirect host plant resistance, such as what is seen when herbivore feeding or oviposition on plants triggers the attraction of natural enemies, does not fit into the three traditional categories proposed by Painter (1951). To further our understanding of the interactions between plant defense traits and biological control, experts that can conduct research using natural history, molecular and genetic tools, and field experimentation must be brought together (Agrawal, 2000a).

\section{Practical Implementation of Host Plant Resistance and Biological Control in Integrated Pest Management}

A successful IPM plan must account for the ecology and biology of the targeted pest(s), environmental factors, and agricultural management. It must be localized; a one size fits all approach will never be effective, yet area wide suppression programs encompassing large regions are sometimes necessary (Schellhorn et al., 2015). This is a significant challenge in making prescriptions. An HPR-biological control combination targeting the same pest may work in one region, but not another. Similarly, this combination may work for one type of pest, but not another, even within the same field. While HPR and biological control are two of the key pillars of IPM, other essential management tactics include cultural control and chemical control. Another key management tactic is the "stimulo-deterrent diversion" or "pushpull" strategy. Host plant resistance traits can contribute to the "push" component, while biological control by natural enemies may be enhanced by concentration of pests due to the "pull" component (Eigenbrode et al., 2016). Finding a compromise between the strategies of host plant resistance and biological control may prove to be advantageous for selecting management strategies that maximize pest suppression and minimize the likelihood of resistance by reducing selection pressure on pests. For example, glandular pubescence was bred into commercial potato clones for defense against aphids and leafhoppers (Tingey, 1982). In the absence of natural enemies, aphid populations are the lowest on plants with high trichome density; however, when natural enemies are present, biological control is greatest on plants with intermediate trichome density (Obrycki et al., 1983). Therefore, plants with intermediate trichome density were recommended for potato IPM due to their partial resistance to aphids, compatibility with natural enemies, and reduced risk for development of pest resistance (Obrycki et al., 1983). The concept of pairing a partially resistant crop plant with biological control was proposed by van Emden (1988) as two of the three components of a "pest management triad" for aphid control (the third being use of selective insecticides to cause mortality of pests but not natural enemies). Cortesero et al. (2000) identified leaf domatia, trichomes (in intermediate density), plant signaling via volatiles, and extrafloral nectaries as the most promising plant defense traits for positive synergy with biological control.

Plants experience a wide range of biotic associations (both beneficial and antagonistic) above- and belowground that interact in complex ways (Bezemer and van Dam, 2005; van Dam and Heil, 2011). Herbivory and pathogen pressures experienced belowground can influence above ground interactions between plants, herbivores, and higher trophic levels (e.g., Soler et al., 2007, 2012). Approaches that use beneficial root associates such as arbuscular mycorrhizal fungi and rhizobacteria can not only increase root production and have benefits on yield and aboveground growth, they can stimulate aboveground defensive chemistry providing protection against aboveground herbivores (Gehring and Bennett, 2009; Orrell and Bennett, 2013).

Any recommendations that are given to maximize the compatibility of host plant resistance and biological control must also consider other important agronomic and practical factors, such as water availability and water use efficiency, fertilization and nutrient availability, weed management, and disease management. However, multiple goals can sometimes be achieved by the adoption of a single practice. For example, indirect host plant resistance, pathogen resistance, and biological control can be simultaneously supported in the case with leaf domatia on grape leaves: both predatory and fungivorous mites use these structures for protection and their presence can decrease incidence of arthropod pests and powdery mildew, a major disease of grapes (Agrawal, 2000a; Norton et al., 2000). For crop producers, agronomic traits other than insect resistance, and ultimately yield, will be the deciding factors for variety or hybrid selection. For crops where the seed market is dominated by transgenics, there may be less choice for the farmer; often only the highest yielding hybrids are chosen for transformation; in order to have the $\mathrm{Bt}$ or herbicide resistance traits desired, a smaller pool of varieties are available. Plant breeding often focuses on enhancing agronomic traits, such as drought tolerance, with higher yields as a major driving factor. Therefore, breeding for resistance to arthropod pests may not be the highest priority. Many plant defense traits have been inadvertently lost or weakened through domestication and selective breeding to enhance yields (Brattsen, 1991; Loughrin et al., 1995; Pickett et al., 1997; Rasmann et al., 2005; Chen et al., 2015a,b). Often, indirect defenses that rely upon the attraction or provisioning of natural enemies have also been lost, although efforts have been made to restore these plant traits, such as $\mathrm{E} \beta \mathrm{C}$-production due to an oregano transgene in maize to attract nematodes to attack rootworm larvae (see Case study: Maize Volatiles, Western Corn Rootworm, and Entomopathogenic Nematodes) or artificial domatia added to commercial cotton plants, which increased the abundance of certain predators (Agrawal et al., 2000). Wild relatives of cotton do have leaf domatia (Fryxell, 1978) and molecular mapping has been used to identify the genes that affect pubescence in cotton (Wright et al., 1999), allowing for the selective expression of pubescence at the leaf vein axils (domatia) that could positively affect natural enemies and biological control in cotton. Looking back to wild relatives of domesticated plant species could be informative for discovering plant defense traits capable of controlling pest species. 
Host plant resistance and biological control are both wellsuited for adoption in developing countries due to their low cost and lack of need for specialized equipment. The costs of HPR are often built into the price of seed (and may be a one-time expense if farmers can harvest and plant their own seeds subsequently). Biological control may be completely free, if natural control or conservation biological control is used. However, the use of entomopathogens may require application equipment. These biological control methods are in contrast to other types of management, such as chemical control, which may require the use of expensive equipment that is not accessible to farmers in developing countries. A review of these considerations can be found in Thomas and Waage (1996). Finally, HPR and biological control are compatible with the ecological intensification theory of agricultural production, which focuses on the conservation and promotion of biodiversity to support ecosystem services in cropland (Geertsema et al., 2016).

\section{CONCLUSION}

In one of the first reviews to address the interactions between host plant resistance and biological control for pest management, Bergman and Tingey (1979) stated that "interactions between plant resistance and arthropod predators and parasites remain poorly known." Since that time, a large body of literature has

\section{REFERENCES}

Agrawal, A., Karban, R., and Colfer, R. (2000). How leaf domatia and induced resistance affect herbivores, natural enemies and plant performance. Oikos 89, 70-80. doi: 10.1034/j.1600-0706.2000.890108.x

Agrawal, A., Kobayashi, C., and Thaler, J. S. (1999). Influence of prey availability and induced host-plant resistance on omnivory by western flower thrips. Ecology 80, 518-523. doi: 10.1890/0012-9658(1999)080[0518:IOPAAI]2.0.CO;2

Agrawal, A. A. (2000a). Mechanisms, ecological consequences and agricultural implications of tri-trophic interactions. Curr. Opin. Plant Biol. 3, 329-395. doi: 10.1016/S1369-5266(00)00089-3

Agrawal, A. A. (2000b). Specificity of induced resistance in wild radish: causes and consequences for two specialist and two generalist caterpillars. Oikos 89, 493-500. doi: 10.1034/j.1600-0706.2000.890308.x

Agrawal, A. A. (2011). Current trends in the evolutionary ecology of plant defence. Funct. Ecol. 25, 420-432. doi: 10.1111/j.1365-2435.2010.01796.x

Agrawal, A. A., and Karban, R. (1997). Domatia mediate plant-arthropod mutualism. Nature 387, 562-563. doi: 10.1038/42384

Alba, J. M., Bleeker, P. M., Glas, J. J., Schimmel, B. C. J., Wijk, M., van Sabelis, M. W., et al. (2012). "The impact of induced plant volatiles on plant-arthropod interactions," in Arthropod-Plant Interactions, eds G. Smagghe and I. Diaz (Dordrecht: Springer International), 15-73.

Alborn, H. T., Turlings, T. C. J., Jones, T. H., Stenhagen, G., Loughrin, J. H., and Tumlinson, J. H. (1997). An elicitor of plant volatiles from beet armyworm oral secretion. Science 276, 945-949. doi: 10.1126/science.276.5314.945

Ali, J. G., and Agrawal, A. A. (2012). Specialist versus generalist insect herbivores and plant defense. Trends Plant Sci. 17, 293-302. doi: 10.1016/j.tplants.2012. 02.006

Anbesse, S., and Ehlers, R.-U. (2013). Heterorhabditis sp. not attracted to synthetic (E)- $\beta$-caryophyllene, a volatile emitted by roots upon feeding by corn rootworm. J. Appl. Entomol. 137, 88-96. doi: 10.1111/j.1439-0418.2012.01753.x

Armer, C. A., Berry, R. E., and Kogan, M. (2000). Longevity of phytophagous heteropterans predators feeding on transgenic Btt-potato plants. Entomol. Exp. Appl. 95, 329-333. doi: 10.1046/j.1570-7458.2000.00672.x addressed this important question. However, we will need to continue to explore the dynamic interactions between host plant resistance and biological control as these tritrophic interactions are impacted by changing global conditions, such as climate. It is now clear that the mechanisms by which plant defense traits and natural enemies interact are complex and may be synergistic, disruptive, or anywhere on the continuum between. Each is clearly a powerful tool for suppressing herbivore populations and continued efforts to utilize these methods in IPM are essential for environmentally and economically sustainable global crop production. This review provided synthesis for the many facets of these interactions and encompassed the many critical implications these interactions have for agriculture today.

\section{AUTHOR CONTRIBUTIONS}

All authors listed, have made substantial, direct and intellectual contribution to the work, and approved it for publication.

\section{ACKNOWLEDGMENT}

We would like to acknowledge the improvements to this manuscript made by comments from the three reviewers.

Arpaia, S., Gould, F., and Kennedy, G. (1997). Potential impact of Coleomegilla maculata predation on adaptation of Leptinotarsa decemlineata to Bt-transgenic potatoes. Entomol. Exp. Appl. 82, 91-100. doi: 10.1046/j.1570-7458.1997. 00117.x

Arthropod Pesticide Resistance Database (2016)). Arthropod Pesticide Resistance Database. Available at: www.pesticideresistance.org/

Athey, K. J., Dreyer, J., Kowles, K. A., Penn, H. J., Sitvarin, M. I., and Harwood, J. D. (2016). Spring forward: molecular detection of early season predation in agroecosystems. Food Webs doi: 10.1016/j.fooweb.2016.06.001

Bachman, P. M., Bolognesi, R., Moar, W. J., Mueller, G. M., Paradise, M. S., Ramaseshadri, P., et al. (2013). Characterization of the spectrum of insecticidal activity of a double-stranded RNA with targeted activity against Western Corn Rootworm (Diabrotica virgifera virgifera LeConte). Transgenic Res. 22, 1207-1222. doi: 10.1007/s11248-013-9716-5

Baker, E. A. (1974). The influence of environment on leaf wax development in Brassica oleracea var. gemmifera. New Phytol. 73, 955-966. doi: 10.1111/j.14698137.1974.tb01324.x

Bakker, F. M., and Klein, M. E. (1992). "How cassava plants enhance the efficacy of their phytoseiid bodyguards," in Proceedings of the 8th International Symposium on Insect-Plant Relationships, Dordrecht. 353-354.

Ballhorn, D. J., Kautz, S., and Heil, M. (2013). Distance and sex determine host plant choice by herbivorous beetles. PLOS ONE 8:e55602. doi: 10.1371/journal. pone.0055602

Barbosa, P., Gross, P., and Kemper, J. (1991). Influence of plant allelochemicals on the tobacco hornworm and its parasitoid, Cotesia congregata. Ecology 72, 1567-1575. doi: 10.2307/1940956

Barbosa, P., Saunders, J. A., Kemper, J., Trumbule, R., Olechno, J., and Martinat, P. (1986). Plant allelochemicals and insect parasitoids: effects of nicotine on Cotesia congregata (Say) (Hymenoptera: Braconidae) and Hyposoter annulipes (Cresson) (Hymenoptera: Ichneumonidae). J. Chem. Ecol. 12, 1319-1328. doi: 10.1007/BF01012351

Baum, J. A., Bogaert, T., Clinton, W., Heck, G. R., Feldmann, P., Ilagan, O., et al. (2007). Control of coleopteran insect pests through RNA interference. Nat. Biotechnol. 25, 1322-1326. doi: 10.1038/nbt1359 
Baur, M. E., and Boethel, D. J. (2003). Effect of Bt-cotton expressing CrylA(c) on the survival and fecundity of two hymenopteran parasitoids (Braconidae, Encyrtidae) in the laboratory. Biol. Control 26, 325-332. doi: 10.1016/S10499644(02)00160-3

Bellows, T. S., Fisher, T. W., Caltagirone, L. E., Dahlsten, D. L., Gordh, G., and Huffaker, C. B. (1999). Handbook of Biological Control. Amsterdam: Elsevier.

Benrey, B., and Denno, R. F. (1997). The slow-growth-high-mortality hypothesis: a test using the cabbage butterfly and its larval parasitoid. Ecology 78, 987-999. doi: 10.1890/0012-9658(1997)078[0987:TSGHMH]2.0.CO;2

Bentley, B. L. (1977). Extrafloral nectaries and protection by pugnacious bodyguards. Annu. Rev. Ecol. Evol. Syst. 8, 407-427. doi: 10.1146/annurev.es. 08.110177 .002203

Bentley, B. L. (1983). "Nectaries in agriculture, with an emphasis on the tropics," in The Biology of Nectaries, eds B. Bentley and T. Elias (New York, NY: Columbia University Press), 204-222.

Berenbaum, M. R. (1983). Coumarins and caterpillars: a case for coevolution. Evolution 37, 163-179. doi: 10.2307/2408184

Berenbaum, M. R. (1990). Evolution of specialization in insect-umbellifer associations. Annu. Rev. Entomol. 35, 319-343. doi: 10.1146/annurev.en.35. 010190.001535

Bergman, J. M., and Tingey, W. M. (1979). Aspects of interaction between plant genotypes and biological control. Bull. Entomol. Soc. Am. 25, 275-279. doi: $10.1093 /$ besa/25.4.275

Bernal, J. S. (2010). "Genetically modified crops and biological control with egg parasitoids," in Egg Parasitoids in Agroecosystems with Emphasis on Trichogramma, eds F. Consoli, J. R. Parra, and R. A. Zucchi (Dordrecht: Springer International), 443-465.

Bernal, J. S., Griset, J. G., and Gillogly, P. O. (2002). Impacts of developing on Bt maize intoxicated hosts on fitness parameters of a stem borer parasitoid. J. Entomol. Sci. 37, 27-40.

Bernal, J. S., Prasifka, J. R., Sétamou, M., and Heinz, K. M. (2004). "Transgenic insecticidal cultivars in integrated pest management: challenges and opportunities," in Integrated Pest Management: Potential, Constraints and Challenges, eds O. Koul, G. S. Dhaliwal, and G. W. Cuperus (Oxfordshire: CAB International), 123-145.

Bernays, E. A., and Graham, M. (1988). On the evolution of host specificity in phytophagous arthropods. Ecology 69, 886-892. doi: 10.2307/1941237

Bezemer, T. M., and van Dam, N. M. (2005). Linking aboveground and belowground interactions via induced plant defenses. Trends Ecol. Evol. 20, 617-624. doi: 10.1016/j.tree.2005.08.006

Birch, A. N. E., Geoghegan, I. E., Majerus, M. E. N., McNicol, J. W., Hackett, C. A., Gatehouse, A. M. R., et al. (1999). Tri-trophic interactions involving pest aphids, predatory 2-spot ladybirds and transgenic potatoes expressing snowdrop lectin for aphid resistance. Mol. Breed. 5, 75-83. doi: 10.1023/A:1009659316170

Bolognesi, R., Ramaseshadri, P., Anderson, J., Bachman, P., Clinton, W., Flannagan, R., et al. (2012). Characterizing the mechanism of action of doublestranded RNA activity against western corn rootworm (Diabrotica virgifera virgifera LeConte). PLoS ONE 7:e47534. doi: 10.1371/journal.pone.0047534

Bottger, G. T., and Patana, R. (1966). Growth, development and survival of certain Lepidoptera fed gossypol in the diet. J. Econ. Entomol. 59, 1166-1169. doi: 10.1093/jee/59.5.1166

Bottrell, D. G., Barbosa, P., and Gould, F. (1998). Manipulating natural enemies by plant variety selection and modification: a realistic strategy? Annu. Rev. Entomol. 43, 347-367. doi: 10.1146/annurev.ento.43.1.347

Brattsen, L. B. (1991). Bioengineering of crop plants and resistant biotype evolution in insects: counteracting coevolution. Arch. Insect. Biochem. Physiol. 17, 253 267. doi: 10.1002/arch.940170408

Bruinsma, M., Posthumus, M. A., Mumm, R., Mueller, M. J., van Loon, J. J. A., and Dicke, M. (2009). Jasmonic acid-induced volatiles of Brassica oleracea attract parasitoids: effects of time and dose, and comparison with induction by herbivores. J. Exp. Bot. 60, 2575-2587. doi: 10.1093/jxb/erp101

Buitenhuis, R., Shipp, L., Scott-Dupree, C., Brommit, A., and Lee, W. (2014). Host plant effects on the behavior and performance of Amblyseius swirskii (Acari: Phytoseiidae). Exp. Appl. Acarol. 62, 171-180. doi: 10.1007/s10493-0139735-1

Bush, G. L. (1974). "Sympatric speciation in phytophagous parasitic insects," in Evolutionary Strategies of Parasitic Insects and Mites, ed. P. W. Price (New York, NY: Plenum), 187-206.
Cameron, J. W., and Anderson, L. D. (1966). Husk tightness, earworm egg numbers, and starchiness of kernels in relation to resistance of corn to the corn earworm. J. Econ. Entomol. 59, 556-558. doi: 10.1093/jee/59.3.556

Campbell, B. C., and Duffey, S. S. (1979). Tomatine and parasitic wasps: potential incompatibility of plant antibiosis with biological control. Science 205, 700-702. doi: 10.1126/science.205.4407.700

Carriére, Y., Ellers-Kirk, C., Sisterson, M., Antillam, L., Whitlow, M., Dennehy, T. J., et al. (2003). Long-term regional suppression of pink bollworm by Bacillus thuringiensis cotton. Proc. Natl. Acad. Sci. U.S.A. 100, 1519-1523. doi: 10.1073/ pnas.0436708100

Casacuberta, J. M., Devos, Y., du Jardin, P., Ramon, M., Vaucheret, H., and Nogue, F. (2015). Biotechnological uses of RNAi in plants: risk assessment considerations. Trends Biotechnol. 33, 145-147. doi: 10.1016/j.tibtech.2014. 12.003

Chapman, R. F. (1977). The role of the leaf surface in food selection by acridids and other insects. Colloq. Int. Centre Natl. Rech. Sci. 265, 133-149.

Chen, M., Ye, G. Y., Liu, Z. C., Fang, Q., Hu, C., Peng, Y. F., et al. (2009). Analysis of Cry1 Ab toxin bioaccumulation in a food chain of Bt rice, an herbivore and a predator. Ecotoxicology 18, 230-238. doi: 10.1007/s10646-008-0276-z

Chen, Y. H., Gols, R., and Benrey, B. (2015a). Crop domestication and its impact on naturally selected trophic interactions. Annu. Rev. Entomol. 60, 35-58. doi: 10.1146/annurev-ento-010814-020601

Chen, Y. H., Gols, R., Stratton, C. A., Brevik, K. A., and Benrey, B. (2015b). Complex tritrophic interactions in response to crop domestication: predictions from the wild. Entomol. Exp. Appl. 157, 40-59. doi: 10.1111/eea.12344

Ciosi, M., Toepfer, S., Li, H., Haye, T., Kuhlmann, U., Wang, H., et al. (2009). European populations of Diabrotica virgifera virgifera are resistant to aldrin, but not methyl-parathion. J. Appl. Entomol. 133, 307-314. doi: 10.1111/j.14390418.2008.01363.x

Cook, O. F. (1904). An enemy of the cotton-boll-weevil. Science 19, 862-864. doi: 10.1126/science.19.492.862-a

Cook, O. F. (1905). Habits of the Kelep or Guatemalan cotton boll weevil ant. U. S. Dep. Agric. Bull. Bureau Entomol. 49, 1-15.

Cortesero, A. M., Stapel, J. O., and Lewis, W. J. (2000). Understanding and manipulating plant attributes to enhance biological control. Biol. Control 17, 35-49. doi: 10.1006/bcon.1999.0777

Culpepper, A. S. (2006). Glyphosate induced weed shifts. Weed Technol. 20, 277-281. doi: 10.1073/pnas.1013154107

De Clercq, P., Mohaghegh, J., and Tirry, L. (2000). Effect of host plant on the functional response of the predator Podisus nigrispinus (Heteroptera: Pentatomidae). Biol. Control 18, 65-70. doi: 10.1006/bcon.1999.0808

De Geyter, N., Gholami, A., Goormachtig, S., and Goossens, A. (2012). Transcriptional machineries in jasmonate-elicited plant secondary metabolism. Trends Plant Sci. 17, 349-359. doi: 10.1016/j.tplants.2012.03.001

De Moraes, C. M., Lewis, W. J., Paré, P. W., Alborn, H. T., and Tumlinson, J. H. (1998). Herbivore-infested plants selectively attract parasitoids. Nature 393, 570-573. doi: 10.1038/31219

Degen, T., Dillmann, C., Marion-Poll, F., and Turlings, T. C. J. (2004). High genetic variability of herbivore-induced volatile emission within a broad range of maize inbred lines. Plant Physiol. 135, 1928-1938. doi: 10.1104/pp.104.039891

Degenhardt, J., Gershenzon, J., Baldwin, I. T., and Kessler, A. (2003). Attracting friends to feast on foes: engineering terpene emission to make crop plants more attractive to herbivore enemies. Curr. Opin. Biotechnol. 14, 169-176. doi: 10.1016/S0958-1669(03)00025-9

Degenhardt, J., Hiltpold, I., Köllner, T. G., Frey, M., Gierl, A., Gershenzon, J., et al. (2009). Restoring a maize root signal that attracts insect-killing nematodes to control a major pest. Proc. Natl. Acad. Sci. U.S.A. 106, 13213-13218. doi: 10.1073/pnas.0906365106

Dicke, M. (1999). Are herbivore-induced plant volatiles reliable indicators of herbivore identity to foraging carnivorous arthropods? Entomol. Exp. Appl. 91, 131-142. doi: 10.1046/j.1570-7458.1999.00475.x

Dicke, M. (2009). Behavioural and community ecology of plants that cry for help. Plant Cell Environ. 32, 654-665. doi: 10.1111/j.1365-3040.2008.01913.x

Dicke, M. (2015). Herbivore-induced plant volatiles as a rich source of information for arthropod predators: fundamental and applied aspects. J. Indian Inst. Sci. 95, $35-42$.

Duan, J. J., Head, G., McKee, M. J., Nickson, T. E., Martin, J. H., and Sayegh, F. S. (2002). Evaluation of dietary effects of transgenic corn pollen expressing 
Cry3Bb1 protein on a non-target ladybird beetle, Coleomegilla maculata. Entomol. Exp. Appl. 104, 271-280. doi: 10.1046/j.1570-7458.2002.01013.x

Duan, J. J., Lundgren, J. G., Naranjo, S. E., and Marvier, M. (2010). Extrapolating non-target risk of Bt crops from laboratory to field. Biol. Lett. 6, 74-77. doi: 10.1098/rsbl.2009.0612

Duan, X. L., Hou, Q. L., and Liang, R. Q. (2015). Expression of two synthetic lectin genes sGNA and sNTL in transgenic wheat enhanced resistance to aphids. Res. J. Biotechnol. 10, 11-18.

Dudareva, N., Klempien, A., Muhlemann, J. K., and Kaplan, I. (2013). Biosynthesis, function and metabolic engineering of plant volatile organic compounds. New Phytol. 198, 16-32. doi: 10.1111/nph.12145

Dutton, A., Klein, H., Romeis, J., and Bigler, F. (2002). Uptake of Bt-toxin by herbivores feeding on transgenic maize and consequences for the predator Chrysoperla carnea. Ecol. Entomol. 27, 441-447. doi: 10.1046/j.1365-2311.2002. 00436.x

Eigenbrode, S. D., Birch, A. N. E., Lindzey, S., Meadow, R., and Snyder, W. E. (2016). A mechanistic framework to improve understanding and application of push-pull systems in pest management. J. Appl. Ecol. 53, 202-212. doi: 10. $1111 / 1365-2664.12556$

Eigenbrode, S. D., Castagnola, T., Roux, M.-B., and Steljes, L. (1996). Mobility of three generalist predators is greater on cabbage with glossy leaf wax than on cabbage with a wax bloom. Entomol. Exp. Appl. 81, 335-343. doi: 10.1046/j. 1570-7458.1996.00104.x

Eigenbrode, S. D., and Espelie, K. E. (1995). Effects of plant epicuticular lipids on insect herbivores. Annu. Rev. Entomol. 40, 171-194. doi: 10.1146/annurev.en. 40.010195.001131

Eigenbrode, S. D., Espelie, K. E., and Shelton, A. M. (1991a). Behavior of neonate diamondback moth larvae [Plutella xylostella (L.)] on leaves and on extracted leaf waxes of resistant and susceptible cabbages. J. Chem. Ecol. 17, 1691-1704. doi: 10.1007/BF00984697

Eigenbrode, S. D., and Jetter, R. (2002). Attachment to plant surface waxes by an insect predator. Integr. Comp. Biol. 42, 1091-1099. doi: 10.1093/icb/42.6.1091

Eigenbrode, S. D., Kabalo, N. N., and Stoner, K. A. (1999). Predation, behavior, and attachment by Chrysoperla plorabunda larvae on Brassica oleracea with different surface waxblooms. Entomol. Exp. Appl. 90, 225-235. doi: 10.1046/j.1570-7458. 1999.00443.x

Eigenbrode, S. D., Moodie, S., and Castagnola, T. (1995). Predators mediate host plant resistance to a phytophagous pest in cabbage with glossy leaf wax. Entomol. Exp. Appl. 77, 335-342. doi: 10.1111/j.1570-7458.1995.tb02331.x

Eigenbrode, S. D., and Shelton, A. M. (1990). Behavior of neonate diamondback moth larvae (Lepidoptera: Plutellidae) on glossy-leafed resistant Brassica oleracea L. Environ. Entomol. 19, 1566-1571. doi: 10.1093/ee/19.5.1566

Eigenbrode, S. D., Stoner, K. A., Shelton, A. M., and Kain, W. C. (1991b). Characteristics of glossy leaf waxes associated with resistance to diamondback moth (Lepidoptera: Plutellidae) in Brassica oleracea. J. Econ. Entomol. 84, 1609-1618. doi: 10.1093/jee/84.5.1609

Eilenberg, J., Hajek, A., and Lomer, C. (2001). Suggestions for unifying the terminology in biological control. Biocontrol 46, 387-400. doi: 10.1023/A: 1014193329979

Eubanks, M. D., and Denno, R. F. (1999). The ecological consequences of variation in plants and prey for an omnivorous insect. Ecology 80, 1253-1266. doi: 10. 1890/0012-9658(1999)080[1253:TECOVI]2.0.CO;2

Fearing, P. L., Brown, D., Vlachos, D., Meghji, M., and Privalle, L. (1997). Quantitative analysis of CryIA(b) expression in Bt maize plants, tissues, and silage and stability of expression over successive generations. Mol. Breed. 3, 167-176. doi: 10.1023/A:1009611613475

Felton, G. W., and Tumlinson, J. H. (2008). Plant-insect dialogs: complex interactions at the plant-insect interface. Trends Plant Sci. 17, 250-259. doi: 10.1016/j.pbi.2008.07.001

Ferry, N., Mulligan, E. A., Stewart, C. N., Tabashnik, B. E., Port, G. R., and Gatehouse, A. M. R. (2006). Prey-mediated effects of transgenic canola on a beneficial, non-target, carabid beetle. Transgenic Res. 15, 501-514. doi: 10.1007/ s11248-006-0021-4

Fox, L. R., Letourneau, D. K., Eisenbach, J., and van Nouhuys, S. (1990). Parasitism rates and sex ratios of a parasitic wasp: effects of herbivore and plant quality. Oecologia 83, 414-419. doi: 10.1007/BF00317569

Francis, F., Lognay, G., Wathelet, J.-P., and Haubruge, E. (2001). Effects of allelochemicals from first (Brassicaceae) and second (Myzus persicae and
Brevicoryne brassicae) trophic levels on Adalia bipunctata. J. Chem. Ecol. 27, 243-256. doi: 10.1023/A:1005672220342

Fryxell, P. A. (1978). The Natural History of the Cotton Tribe. College Station, TX: Texas A \& M University Press.

Garcia, M., Ortego, F., Castanera, P., and Farinos, G. P. (2012). Assessment of preymediated effects of the coleopteran-specific toxin Cry3Bb1 on the generalist predator Atheta coriaria (Coleoptera: Staphylinidae). Bull. Entomol. Res. 102, 293-302. doi: 10.1017/S0007485311000666

Gassmann, A. J., Petzold-Maxwell, J. L., Keweshan, R. S., and Dunbar, M. W. (2011). Field-evolved resistance to Bt maize by western corn rootworm. PLoS ONE 6:e22629. doi: 10.1371/journal.pone.0022629

Gatehouse, A. M. R., Down, R. E., Powell, K. S., Sauvion, N., Rahb, Y., Newell, C. A., et al. (1996). Effects of GNA-expressing transgenic potato plants on peachpotato aphid, Myzus persicae. Entomol. Exp. Appl. 79, 295-307. doi: 10.1111/ j.1570-7458.1996.tb00837.x

Geertsema, W., Rossing, W. A. H., Landis, D. A., Bianchi, F. J. J. A., van Rijn, P. C. J., Schaminée, J. H. J., et al. (2016). Actionable knowledge for ecological intensification of agriculture. Front. Ecol. Environ. 14:209-216. doi: 10.1002/ fee. 1258

Geervliet, J. B. F., Ariëns, S., Dicke, M., and Vet, L. E. M. (1998). Longdistance assessment of patch profitability through volatile infochemicals by the parasitoids Cotesia glomerata and C. rubecula (Hymenoptera: Braconidae). Biol. Control 11, 113-121. doi: 10.1006/bcon.1997.0585

Gehring, C., and Bennett, A. (2009). Mycorrhizal fungal-plant-insect interactions: the importance of a community approach. Environ. Entomol. 38, 93-102. doi: $10.1603 / 022.038 .0111$

Geng, J.-H., Shen, Z.-R., Song, K., and Zheng, L. (2006). Effect of pollen of regular cotton and transgenic $\mathrm{Bt}+\mathrm{CpTI}$ cotton on the survival and reproduction of the parasitoid wasp Trichogramma chilonis (Hymenoptera: Trichogrammatidae) in the laboratory. Environ. Entomol. 35, 1661-1668. doi: 10.1093/ee/35. 6.1661

Ghising, K., Harmon, J. P., Beauzay, P. B., Prischmann-Voldseth, D. A., Helms, T. C., Ode, P. J., et al. (2012). Impact of Rag1 aphid resistant soybeans on Binodoxys communis (Hymenoptera: Braconidae), a parasitoid of soybean aphid (Hemiptera: Aphididae). Environ. Entomol. 41, 282-288. doi: 10.1603/ EN11196

Gols, R., Bukovinsky, T., van Dam, N. M., Dicke, M., Bullock, J. M., and Harvey, J. A. (2008a). Performance of generalist and specialist herbivores and their endoparasitoids differs on cultivated and wild Brassica populations. J. Chem. Ecol. 34, 132-143. doi: 10.1007/s10886-008-9429-z

Gols, R., Witjes, L. M. A., van Loon, J. J. A., Posthumus, M. A., Dicke, M., and Harvey, J. A. (2008b). The effect of direct and indirect defenses in two wild brassicaceous plant species on a specialist herbivore and its gregarious endoparasitoid. Entomol. Exp. Appl. 128, 99-108. doi: 10.1111/j.1570-7458. 2008.00681.x

Gould, F., Kennedy, G. G., and Johnson, M. T. (1991). Effects of natural enemies on the rate of herbivore adaptation to resistant host plants. Entomol. Exp. Appl. 58, 1-14. doi: 10.1111/j.1570-7458.1991.tb01445.x

Gray, M. E., Sappington, T. W., Miller, N. J., Moeser, J., and Bohn, M. O. (2009). Adaptation and invasiveness of western corn rootworm: intensifying research on a worsening pest. Annu. Rev. Entomol. 54, 303-321. doi: 10.1146/annurev. ento.54.110807.090434

Grazia-Tommasini, M. (1995). "Frankliniella occidentalis and other thrips harmful to vegetable and ornamental crops in Europe," in Biological Control of Thrips Pests, eds A. J. M. Loomans, J. C. van Lenteren, M. G. Tommasini, S. Maini, and J. Riudavets (Wageningen: Wageningen Agricultural University Press), 1-42.

Grossi-de-Sa, M. F., Lucena, W., Souza, M. L., Nepomuceno, A. L., Osir, E. O., Amugune, N., et al. (2006). "Transgene expression and locus structure of Bt cotton," in Environmental Risk Assessment of Genetically Modified OrganismsMethodologies for Assessing Bt Cotton in Brazil, eds A. Hilbeck, D. A. Andow, and E. M. G. Fontes (Wallingford: CAB International), 93-107.

Gunasena, G. H., Vinson, S. B., Williams, H. J., and Stipanovic, R. D. (1989). Development and survival of the endoparasitoid Campoletis sonorensis (Hymenoptera: Ichneumonidae) reared from gossypol exposed Heliothis virescens (F) (Lepidoptera: Noctuidae). Environ. Entomol. 18, 886-891. doi: 10.1093/ee/18.5.886

Hagenbucher, S., Olson, D. M., Ruberson, J. R., Wäckers, F. L., and Romeis, J. (2013a). Resistance mechanisms against arthropod herbivores in cotton and 
their interactions with natural enemies. Crit. Rev. Plant Sci. 32, 458-482. doi: 10.1080/07352689.2013.809293

Hagenbucher, S., Wäckers, F. L., and Romeis, J. (2014a). Aphid honeydew quality as a food source for parasitoids is maintained in Bt cotton. PLoS ONE 9:e107806. doi: 10.1371/journal.pone.0107806

Hagenbucher, S., Wäckers, F. L., and Romeis, J. (2014b). Indirect multi-trophic interactions mediated by induced plant resistance: impact of caterpillar feeding on aphid parasitoids. Biol. Lett. 10:20130795. doi: 10.1098/rsbl.2013.0795

Hagenbucher, S., Wäckers, F. L., Wettstein, F. E., Olson, D. M., Ruberson, J. R., and Romeis, J. (2013b). Pest trade-offs in technology: reduced damage by caterpillars in Bt cotton benefits aphids. Proc. R. Soc. B 280: 20130042. doi: $10.1098 /$ rspb.2013.0042

Hajek, A. E. (2004). Natural Enemies. New York, NY: Cambridge University Press.

Halkier, B. A., and Gershenzon, J. (2006). Biology and biochemistry of glucosinolates. Annu. Rev. Plant Biol. 57, 303-333. doi: 10.1146/annurev. arplant.57.032905.105228

Hamm, J. J., and Wiseman, B. R. (1986). Plant resistance and nuclear polyhedrosis virus for suppression of fall armyworm (Lepidoptera: Noctuidae). Fla. Entomol. 69, 541-549. doi: 10.2307/3495388

Han, Y., Chen, J., Wang, H., Zhao, J., He, Y., and Hua, H. (2015). Prey-mediated effects of transgenic cry2Aa rice on the spider Hylyphantes graminicola, a generalist predator of Nilaparvata lugens. BioControl 60, 251-261. doi: 10.1007/ s10526-014-9629-0

Harvey, J. A., and Gols, R. (2011). Population-related variation in plant defense more strongly affects survival of an herbivore than its solitary parasitoid wasp. J. Chem. Ecol. 37, 1081-1090. doi: 10.1007/s10886-011-0024-3

Harwood, J. D., Samson, R. A., and Obrycki, J. J. (2007). Temporal detection of CrylAb-endotoxins by coccinellid predators in fields of Bacillus thuringiensis corn. Bull. Entomol. Res. 97, 643-648. doi: 10.1017/S000748530700524X

Harwood, J. D., Wallin, H., and Obrycki, J. J. (2005). Uptake of Bt-endotoxins by non-target herbivores and higher order arthropod predators: molecular evidence from a transgenic corn agroecosystem. Mol. Ecol. 14, 2815-2823. doi: 10.1111/j.1365-294X.2005.02611.x

Hawley, C. J., Peairs, F. B., and Randolph, T. L. (2003). Categories of resistance at different growth stages in halt, a winter wheat resistant to the Russian wheat aphid (Homoptera: Aphididae). J. Econ. Entomol. 96, 214-219. doi: 10.1093/jee/ 96.1.214

Heard, M. S., Rothery, P., Perry, J. N., and Firbank, L. G. (2005). Predicting longterm changes in weed populations under GMHT crop management. Weed Res. 45, 331-338. doi: 10.1111/j.1365-3180.2005.00465.x

Heil, M. (2008). Indirect defence via tritrophic interactions. New Phytol. 178, 41-61. doi: 10.1111/j.1469-8137.2007.02330.x

Heil, M. (2014). Herbivore-induced plant volatiles: targets, perception and unanswered questions. New Phytol. 204, 297-306. doi: 10.1111/nph.12977

Heil, M. (2015). Extrafloral nectar at the plant-insect interface: a spotlight on chemical ecology, phenotypic plasticity, and food webs. Annu. Rev. Entomol. 60, 213-232. doi: 10.1146/annurev-ento-010814-020753

Heil, M., and Ton, J. (2008). Long-distance signaling in plant defence. Trends Plant Sci. 13, 264-272. doi: 10.1016/j.tplants.2008.03.005

Heimpel, G. E., Neuhauser, C., and Andow, D. A. (2005). Natural enemies and the evolution of resistance to transgenic insecticidal crops by pest insects: the role of egg mortality. Environ. Entomol. 34, 512-526. doi: 10.1603/0046-225X-34.3.512

Higley, L. G., and Peterson, R. K. D. (2009). "Economic decision rules for IPM," in Integrated Pest Management: Concepts, Tactics, Strategies and Case Studies, eds E. B. Radcliffe, W. D. Hutchison, and R. E. Cancelado (New York, NY: Cambridge University Press), 25-32.

Hilbeck, A., Baumgartner, M., Fried, P. M., and Bigler, F. (1998a). Effects of transgenic Bacillus thuringiensis corn-fed prey on mortality and development time of immature Chrysoperla carnea (Neuroptera: Chrysopidae). Environ. Entomol. 27, 480-487. doi: 10.1093/ee/27.5.1255

Hilbeck, A., Moar, W. J., Pusztai-Carey, M., Filippini, A., and Bigler, F. (1998b). Toxicity of Bacillus thuringiensis CrylAb toxin to the predator Chrysoperla carnea (Neuroptera: Chrysopidae). Environ. Entomol. 27, 1255-1263. doi: 10. 1093/ee/27.5.1255

Hilbeck, A., and Otto, M. (2015). Specificity and combinatorial effects of Bacillus thuringiensis cry toxins in the context of GMO environmental risk assessment. Front. Environ. Sci. 3:71. doi: 10.3389/fenvs.2015.00071
Hilbeck, A., and Schmidt, J. E. U. (2006). Another view on Bt proteins - how specific are they and what else might they do? Biopestic. Int. 2, 1-50.

Hilfiker, O., Groux, R., Bruessow, F., Kiefer, K., Zeier, J., and Reymond, P. (2014). Insect eggs induce a systemic acquired resistance in Arabidopsis. Plant J. 80, 1085-1094. doi: 10.1111/tpj.12707

Hilker, M., and Meiners, T. (2006). Early herbivore alert: insect eggs induce plant defense. J. Chem. Ecol. 32, 1379-1397. doi: 10.1007/s10886-006-9057-4

Hiltpold, I., Baroni, M., Toepfer, S., Kuhlmann, U., and Turlings, T. C. J. (2010a). Selection of entomopathogenic nematodes for enhanced responsiveness to a volatile root signal helps to control a major root pest. J. Exp. Biol. 213, 2417-2423. doi: 10.1242/jeb.041301

Hiltpold, I., Baroni, M., Toepfer, S., Kuhlmann, U., and Turlings, T. C. J. (2010b). Selective breeding of entomopathogenic nematodes for enhanced attraction to a root signal did not reduce their establishment or persistence after field release. Plant Signal. Behav. 5, 1450-1452. doi: 10.4161/psb.5.11.13363

Hiltpold, I., Erb, M., Robert, C. A. M., and Turlings, T. C. J. (2011). Systemic root signalling in a belowground, volatile-mediated tritrophic interaction. Plant Cell Environ. 34, 1267-1275. doi: 10.1111/j.1365-3040.2011.02327.x

Hiltpold, I., Hibbard, B. E., French, B. W., and Turlings, T. C. J. (2012). Capsules containing entomopathogenic nematodes as a Trojan horse approach to control the western corn rootworm. Plant Soil 358, 11-25. doi: 10.1007/s11104-0121253-0

Hiltpold, I., Toepfer, S., Kuhlmann, U., and Turlings, T. C. J. (2010c). How maize root volatiles affect the efficacy of entomopathogenic nematodes in controlling the western corn rootworm? Chemoecology 20, 155-162. doi: 10.1007/s00049009-0034-6

Holling, C. S. (1966). The functional response of invertebrate predators to prey density. Mem. Can. Entomol. 116, 1109-1121.

Honěk, A. (1993). Intraspecific variation in body size and fecundity in insects: a general relationship. Oikos 66, 483-492. doi: 10.2307/3544943

Horgervorst, P. A. M., Ferry, N., Gatehouse, M. R., Wäckers, F. L., and Romeis, J. (2006). Direct effects of snowdrop lectin (GNA) on larvae of three aphid predators and fate of GNA after ingestion. J. Insect Physiol. 52, 614-624. doi: 10.1016/j.jinsphys.2006.02.011

Hulspas-Jordaan, P. M., and van Lenteren, J. C. (1978). The relationship between host plant leaf structure and parasitisation efficiency of the parasitic wasp Encarsia formosa Gahan (Hymenoptera: Aphelinidae). Meded. Faculteit Landbouww. Rijksuniv. Gent 43, 431-439.

Hutchison, W. D., Burkness, E. C., Mitchell, P. D., Moon, R. D., Leslie, T. W., Fleischer, S. J., et al. (2010). Areawide suppression of European corn borer with Bt maize reaps savings to non-Bt maize growers. Science 330, 222-225. doi: 10.1126/science.1190242

Jackson, J. J. (1996). Field performance of entomopathogenic nematodes for suppression of western corn rootworm (Coleoptera: Chrysomelidae). J. Econ. Entomol. 89, 366-372. doi: 10.1093/jee/89.2.366

Jalalizand, A., Karimy, A., Ashouri, A., Hosseini, M., and Golparvar, A. R. (2012). Effect of host plant morphological features on functional response of Orius albidipennis (Hemiptera: Anthocoridae) to Tetranychus urticae (Acari: Tetranychidae). Res. Crops 13, 378-384.

Jeffries, M. J., and Lawton, J. H. (1984). Enemy free space and the structure of ecological communities. Biol. J. Linn. Soc. 23, 269-286. doi: 10.1007/s11356009-0138-0

Jenkins, J. N., Maxwell, F. G., and Lafever, H. N. (1966). The comparative preference of insects for glanded and glandless cotton. J. Econ. Entomol. 59, 352-356. doi: 10.1093/jee/59.2.352

Johnson, M. T., and Gould, F. (1992). Interaction of genetically engineered host plant resistance and natural enemies of Heliothis virescens (Lepidoptera: Noctuidae) in tobacco. Environ. Entomol. 21, 586-597. doi: 10.1093/ee/21.3. 586

Johnson, M. T., Gould, F., and Kennedy, G. G. (1997a). Effect of an entomopathogen on adaptation of Heliothis virescens populations to transgenic host plants. Entomol. Exp. Appl. 83, 121-135. doi: 10.1046/j.1570-7458.1997. 00165.x

Johnson, M. T., Gould, F., and Kennedy, G. G. (1997b). Effects of natural enemies on relative fitness of Heliothis virescens genotypes adapted and not adapted to resistant host types. Entomol. Exp. Appl. 82, 219-230. doi: 10.1046/j.1570-7458. 1997.00133.x 
Kaplan, I. (2012). Attracting carnivorous arthropods with plant volatiles: the future of biocontrol or playing with fire? Biol. Control 60, 77-89. doi: 10.1016/j. biocontrol.2011.10.017

Kazana, E., Pope, T. W., Tibbles, L., Bridges, M., Pickett, J. A., Bones, A. M., et al. (2007). The cabbage aphid: a walking mustard oil bomb. Proc. R. Soc. B 274, 2271-2277. doi: 10.1098/rspb.2007.0237

Kazmer, D. J., and Luck, R. F. (1995). Field tests of the size-fitness hypothesis in the egg parasitoid Trichogramma pretiosum. Ecology 76, 412-425. doi: 10.2307/ 1941200

Kessler, A. (2015). The information landscape of plant constitutive and induced secondary metabolite production. Curr. Opin. Insect Sci. 8, 47-53. doi: 10.1016/ j.cois.2015.02.002

Kessler, A., and Baldwin, I. T. (2002). Plant responses to insect herbivory: the emerging molecular analysis. Annu. Rev. Plant Biol. 53, 299-328. doi: 10.1146/ annurev.arplant.53.100301.135207

Kim, J., Tooker, J. F., Luthe, D. S., De Moraes, C. M., and Felton, G. W. (2012). Insect eggs can enhance wound response in plants: a study of tomato Solanum lycopersicum L. and Helicoverpa zea Boddie. PLoS ONE 7:e37420. doi: 10.1371/ journal.pone. 0037420

Kirk, W. D. J., and Terry, L. I. (2003). The spread of the western flower thrips Frankliniella occidentalis (Pergande). Agric. For. Entomol. 5, 301-310. doi: 10. 1046/j.1461-9563.2003.00192.x

Kogan, M. (1986). "Plant defense strategies and host-plant resistance," in Ecological Theory and Integrated Pest Management Practice, ed. M. Kogan (New York, NY: John Wiley and Sons), 83-134.

Kogan, M. (1998). Integrated pest management: historical perspectives and contemporary developments. Annu. Rev. Entomol. 43, 243-270. doi: 10.1146/ annurev.ento.43.1.243

Köllner, T. G., Held, M., Lenk, C., Hiltpold, I., Turlings, T. C. J., Gershenzon, J., et al. (2008). A maize (E)- $\beta$-caryophyllene synthase implicated in indirect defense responses against herbivores is not expressed in most American maize varieties. Plant Cell 20, 482-494. doi: 10.1105/tpc.107.051672

Konno, K. (2011). Plant latex and other exudates as plant defense systems: roles of various defense chemicals and proteins contained therein. Phytochemistry 72 , 1510-1530. doi: 10.1016/j.phytochem.2011.02.016

Koptur, S. (1992). "Extrafloral nectary-mediated interactions between insects and plants," in Insect-Plant Interactions, ed. E. Bernays (Boca Raton, FL: CRC Press), $81-129$.

Koveos, D. S., and Broufas, G. D. (2000). Functional response of Euseius finlandicus and Amblyseius andersoni to Panonychus ulmi on apple and peach leaves in the laboratory. Exp. Appl. Acarol. 24, 247-256. doi: 10.1023/A:1006431710313

Krieger, R. I., Feeny, P. P., and Wilkinson, C. F. (1971). Detoxification enzymes in guts of caterpillars: an evolutionary answer to plant defenses. Science 172, 579-581. doi: 10.1126/science.172.3983.579

Krips, O. E., Kleijn, P. W., Willems, P. E. L., Gols, G. J. Z., and Dicke, M. (1999). Leaf hairs influence searching efficiency and predation rate of the predatory mite Phytoseiulus persimilis (Acari: Phytoseiidae). Exp. Appl. Acarol. 23, 119-131. doi: 10.1023/A:1006098410165

Kumar, A., Kumar, N., Siddiqui, A., and Tripathi, C. P. M. (1999). Prey-predator relationship between Lipaphis erysimi Kalt. (Hom., Aphididae) and Coccinella septempunctata L. (Col., Coccinellidae. II. Effect of host plants on the functional response of the predator. J. Appl. Entomol. 125, 591-601. doi: 10.1046/j.14390418.1999.00367.x

Kuo, H.-L. (1986). "Resistance of oats to cereal aphids: effects on parasitism by Aphelinus asychis (Walker)," in Interactions of Plant Resistance and Parasitoids and Predators of Insects, eds D. J. Boethel and R. D. Eikenbary (West Sussex: Ellis Horwood Limited), 125-137.

Kurtz, B., Hiltpold, I., Turlings, T. C. J., Kuhlmann, U., and Toepfer, S. (2009). Comparative susceptibility of larval instars and pupae of the western corn rootworm to infection by three entomopathogenic nematodes. BioControl 54, 255-262. doi: 10.1007/s10526-008-9156-y

Lampert, E. C., Dyer, L. A., and Bowers, M. D. (2010). Caterpillar chemical defense and parasitoid success: Cotesia congregata parasitism of Ceratomia catalpa. J. Chem. Ecol. 36, 992-998. doi: 10.1007/s10886-010-9840-0

Lampert, E. C., Dyer, L. A., and Bowers, M. D. (2011a). Chemical defense across three trophic levels: Catalpa bignonioides, the caterpillar Ceratomia catalpa, and its endoparasitoid Cotesia congregata. J. Chem. Ecol. 37, 1063-1070. doi: 10.1007/s10886-011-0018-1
Lampert, E. C., Zangerl, A. R., Berenbaum, M. R., and Ode, P. J. (2011b). Generalist and specialist host-parasitoid associations respond differently to wild parsnip (Pastinaca sativa) defensive chemistry. Ecol. Entomol. 36, 52-61. doi: 10.1111/j. 1365-2311.2010.01244.x

Lampert, E. C., Zangerl, A. R., Berenbaum, M. R., and Ode, P. J. (2008). Tritrophic effects of xanthotoxin on the polyembryonic parasitoid Copidosoma sosares (Hymenoptera: Encyrtidae). J. Chem. Ecol. 34, 783-790. doi: 10.1007/s10886008-9481-8

Landis, D. A., Wratten, S. D., and Gurr, G. M. (2000). Habitat management to conserve natural enemies of arthropod pests in agriculture. Annu. Rev. Entomol. 45, 175-201. doi: 10.1146/annurev.ento.45.1.175

Lawo, N. C., Wäckers, F. L., and Romeis, J. (2010). Characterizing indirect preyquality mediated effects of a Bt crop on predatory larvae of the green lacewing, Chrysoperla carnea. J. Insect Physiol. 56, 1702-1710. doi: 10.1016/j.jinsphys. 2010.06.012

Laznik, Ž, and Trdan, S. (2013). An investigation on the chemotactic responses of different entomopathogenic nematode strains to mechanically damaged maize root volatile compounds. Exp. Parasitol. 134, 349-355. doi: 10.1016/j.exppara. 2013.03.030

Leather, S. R., and Walsh, P. J. (1993). Sub-lethal plant defenses: the paradox remains. Oecologia 93, 153-155. doi: 10.1007/BF00317663

Lee, J. H., and Kang, T. J. (2004). Functional response of Harmonia axyridis (Pallas) (Coleoptera: Coccinellidae) to Aphis gossypii Glover (Homoptera: Aphididae) in the laboratory. Biol. Control 31, 306-310. doi: 10.1016/j.biocontrol.2004.04.011

Levin, D. A. (1973). The role of trichomes in plant defense. Q. Rev. Biol. 48, 3-15. doi: $10.1086 / 407484$

Levine, E., Spencer, J. L., Isard, S. A., Onstad, D. W., and Gray, M. E. (2002). Adaptation of the western corn rootworm to crop rotation: evolution of a new strain in response to a management practice. Am. Entomol. 48, 94-107. doi: $10.1093 / \mathrm{ae} / 48.2 .94$

Lewis, L. C., Bruck, D. J., Prasifka, J. R., and Raun, E. S. (2009). Nosema pyrausta: its biology, history, and potential role in a landscape of transgenic insecticidal crops. Biol. Control 48, 223-231. doi: 10.1016/j.biocontrol.2008.10.009

Lewis, W. J., and Takasu, K. (1990). Use of learned odours by a parasitic wasp in accordance with host and food needs. Nature 348, 635-636. doi: 10.1038/ $348635 \mathrm{a} 0$

Li, X., Baudry, J., Berenbaum, M. R., and Schuler, M. A. (2004). Structural and functional divergence of insect CYP6B proteins: from specialist to generalist P450. Proc. Natl. Acad. Sci. U.S.A. 101, 2939-2944. doi: 10.1073/pnas. 0308691101

Li, Y., Meissle, M., and Romeis, J. (2008). Consumption of Bt maize pollen expressing Cryl $\mathrm{Ab}$ or Cry3Bb1 does not harm adult green lacewings, Chrysoperla carnea (Neuroptera: Chrysopidae). PLoS ONE 3:e2909. doi: 10. 1371/journal.pone.0002909

Li, Y. H., and Romeis, J. (2009). Impact of snowdrop lectin (Galanthus nivalis agglutinin; GNA) on adults of the green lacewing, Chrysoperla carnea. J. Insect Physiol. 55, 135-142. doi: 10.1016/j.jinsphys.2008.10.015

Lin, J., Eckenrode, C. J., and Dickson, M. H. (1983). Variation in Brassica oleracea resistance to diamondback moth (Lepidoptera: Plutellidae). J. Econ. Entomol. 76, 1423-1427. doi: 10.1093/jee/76.6.1423

Lindgren, P. D., and Lukefahr, M. J. (1977). Effects of nectariless cotton on caged populations of Campoletis sonorensis. Environ. Entomol. 6, 586-588. doi: 10. 1093/ee/6.4.586

Liu, X., Chen, M., Collins, H. L., Onstad, D. W., Roush, R. T., Zhang, Q., et al. (2014). Natural enemies delay insect resistance to Bt crops. PLoS ONE 9:e90366. doi: 10.1371/journal.pone.0090366

Loader, C., and Damman, H. (1991). Nitrogen content of food plants and vulnerability of Pieris rapae to natural enemies. Ecology 72, 1586-1590. doi: $10.2307 / 1940958$

Loughrin, J. H., Manukian, A., Heath, R. R., and Tumlinson, J. H. (1995). Volatiles emitted by different cotton varieties damaged by feeding beet armyworm larvae. J. Chem. Ecol. 21, 1217-1227. doi: 10.1007/BF02228321

Louis, J., Peiffer, M., Ray, S., Luthe, D. S., and Felton, G. W. (2013). Host-specific salivary elicitor(s) of European corn borer induce defenses in tomato and maize. New Phytol. 199, 66-73. doi: 10.1111/nph.12308

Lövei, G. L., and Arpaia, S. (2005). The impact of transgenic plants on natural enemies: a critical review of laboratory studies. Entomol. Exp. Appl. 114, 1-14. doi: 10.1007/s11248-009-9297-5 
Lu, Y., Wu, K., Jiang, Y., Guo, Y., and Desneaux, N. (2012). Widespread adoption of Bt cotton and insecticide decrease promotes biocontrol services. Nature 487, 362-365. doi: 10.1038/nature11153

Lu, Y., Wu, K., Jiang, Y., Xia, B., Li, P., Feng, H., et al. (2010). Mirid bug outbreaks in multiple crops correlated with wide-scale adoption of Bt in cotton. Science 328, 1151-1154. doi: 10.1126/science.1187881

Ludy, C., and Lang, A. (2006). Bt maize pollen exposure and impact on the garden spider, Araneus diadematus. Entomol. Exp. Appl. 118, 145-156. doi: 10.1111/j. 1570-7458.2006.00375.x

Lukefahr, M. J., and Griffin, J. A. (1956). The effects of food on the longevity and fecundity of pink bollworm moths. J. Econ. Entomol. 49, 876-877. doi: 10.1093/jee/49.6.876

Lukefahr, M. J., and Rhyne, C. (1960). Effects of nectariless cottons on populations of three lepidopterous insects. J. Econ. Entomol. 53, 242-244. doi: 10.1093/jee/ 53.2.242

Lundgren, J. G. (2009). Relationships of Natural Enemies and Non-prey Foods. Dordrecht: Springer International.

Lundgren, J. G., and Duan, J. J. (2013). RNAi-based insecticidal crops: potential effects on nontarget species. BioScience 63, 657-665. doi: 10.1525/bio.2013. 63.8 .8

Lundgren, J. G., Gassmann, A. J., Bernal, J., Duan, J. J., and Ruberson, J. (2009a). Ecological compatibility of GM crops and biological control. Crop Prot. 28, 1017-1030. doi: 10.1016/j.cropro.2009.06.001

Lundgren, J. G., Hesler, L. S., Tilmon, K., Dashiell, K., and Scott, R. (2009b). Direct effects of soybean varietal selection and Aphis glycines-resistant soybeans on natural enemies. Arthropod Plant Interact. 3, 9-16. doi: 10.1007/s11829-0089053-4

Lundgren, J. G., and Wiedenmann, R. N. (2002). Coleopteran-specific Cry3Bb toxin from transgenic corn pollen does not affect the fitness of a non-target species, Coleomegilla maculata DeGeer (Coleoptera: Coccinellidae). Environ. Entomol. 31, 1213-1218. doi: 10.1603/0046-225X-31.6.1213

Lutz, W., and Samir, K. C. (2010). Dimensions of global population projections: what do we know about future population trends and structures? Philos. Trans. R. Soc. B 365, 2779-2791. doi: 10.1098/rstb.2010.0133

Macey, M. J. K., and Barber, H. N. (1970). Chemical genetics of wax formation on leaves of Brassica oleracea. Phytochemistry 9, 13-23. doi: 10.1016/S00319422(00)86608-X

Madadi, H., Enkegaard, A., Brodsgaard, H. F., Kharrazi-Pakdel, A., Mohaghegh, J., and Ashouri, A. (2007). Host plant effects on the functional response of Neoseiulus cucumeris to onion thrips larvae. J. Appl. Entomol. 131, 728-733. doi: 10.1111/j.1439-0418.2007.01206.x

Mallampalli, N., Gould, F., and Barbosa, P. (2005). Predation of Colorado potato beetle eggs by a polyphagous ladybeetle in the presence of alternate prey: potential impact on resistance evolution. Entomol. Exp. Appl. 114, 47-54. doi: 10.1111/j.0013-8703.2005.00232.x

Mao, W., Rupasinghe, S., Zangerl, A. R., Schuler, M. A., and Berenbaum, M. R. (2006). Remarkable substrate-specificity of CYP6AB3 in Depressaria pastinacella, a highly specialized caterpillar. Insect Mol. Biol. 15, 169-179. doi: 10.1111/j.1365-2583.2006.00623.x

Marques, R. V., Sarmento, R. A., Lemos, F., Pedro-Neto, M., Sabelis, M. W., Venzon, M., et al. (2015). Active prey mixing as an explanation for polyphagy in predatory arthropods: synergistic dietary effects on egg production despite a behavioural cost. Funct. Ecol. 29, 1317-1324. doi: 10.1111/1365-2435.12439

Marvier, M., McCreedy, C., Regetz, J., and Kareiva, P. (2007). A meta-analysis of effects of Bt cotton and maize on nontarget invertebrates. Science 316, 1475-1477. doi: 10.1126/science. 1139208

Matthews, G. A., and Tunstall, J. P. (1994). Insect Pests of Cotton. Wallingford: CAB International.

Mayntz, D., Raubenheimer, D., Salomon, M., Toft, S., and Simpson, S. J. (2005). Nutrient-specific foraging in invertebrate predators. Science 307, 111-113. doi: 10.1126/science. 1105493

McGovern, J. L., Zangerl, A. R., Ode, P. J., and Berenbaum, M. R. (2006). Furanocoumarins and their detoxification in a tri-trophic interaction. Chemoecology 16, 45-50. doi: 10.1007/s00049-005-0327-3

McKenzie, J. A. (1996). Ecological and Evolutionary Aspects of Insecticide Resistance. Austin, TX: Academic Press.

Meinke, L. J., Siegfried, B. D., Wright, R. J., and Chandler, L. D. (1998). Adult susceptibility of Nebraska western corn rootworm (Coleoptera: Chrysomelidae) populations to selected insecticides. J. Econ. Entomol. 91, 594-600. doi: 10.1093/ jee/91.3.594

Meissle, M., and Romeis, J. (2009). The web-building spider Theridion impressum (Araneae: Theridiidae) is not adversely affected by Bt maize resistant to corn rootworms. Plant Biotechnol. J. 7, 645-656. doi: 10.1111/j.1467-7652.2009. 00431.x

Meissle, M., Vojtech, E., and Poppy, G. M. (2005). Effects of Bt maize-fed prey on the generalist predator Poecilus cupreus L. (Coleoptera: Carabidae). Transgenic Res. 14, 123-132. doi: 10.1007/s11248-004-6458-4

Memelink, J., Verpoorte, R., and Kijne, J. W. (2001). ORCAnization of jasmonateresponsive gene expression in alkaloid metabolism. Trends Plant Sci. 6, 212219. doi: 10.1016/S1360-1385(01)01924-0

Milne, M., and Walter, G. H. (1997). The significance of prey in the diet of the phytophagous thrips, Frankliniella schultzei. Ecol. Entomol. 22, 74-81. doi: 10. 1046/j.1365-2311.1997.00034.x

Mithöfer, A., and Boland, W. (2008). Recognition of herbivory-associated molecular patterns. Plant Physiol. 146, 825-831. doi: 10.1104/pp.107.11 3118

Moran, N., and Hamilton, W. D. (1980). Low nutritive quality as defense against herbivores. J. Theor. Biol. 86, 247-254. doi: 10.1016/0022-5193(80)90004-1

Müller, C. (2008). "Resistance at the plant cuticle," in Induced Plant Resistance to Herbivory, ed. A. Schaller (Dordrecht: Springer-Verlag), 107-129.

Müller, C., Boevé, J.-L., and Brakefield, P. M. (2002). Host plant derived feeding deterrence towards ants in the turnip sawfly Athalia rosae. Entomol. Exp. Appl. 104, 153-157. doi: 10.1046/j.1570-7458.2002.01002.x

Müller, R., de Vos, M., Sun, J. Y., Sønderby, I. E., Halkier, B. A., Wittstock, U., et al. (2010). Differential effects of indole and aliphatic glucosinolates on lepidopteran herbivores. J. Chem. Ecol. 36, 905-913. doi: 10.1007/s10886-0109825-Z

Musser, R. O., Hum-Musser, S. M., Eichenseer, H., Peiffer, M., Ervin, G., Murphy, J. B., et al. (2002). Caterpillar saliva beats plant defences. Nature 416, 599-600. doi: $10.1038 / 416599$ a

Naranjo, S. E. (2009). Risk Assessment: Bt Crops and Invertebrate Non-target EffectsRevisited. ISB News Report: Agricultural and Environmental Biotechnology. Available at: http://www.isb.vt.edu/news/2009/Dec/BtCropsarticle.pdf

Naranjo, S. E. (2011). Impacts of Bt transgenic cotton on integrated pest management. J. Agric. Food Chem. 59, 5842-5851. doi: 10.1021/jf102939c

Naranjo, S. E., Ellsworth, P. C., and Frisvold, G. B. (2015). Economic value of biological control in integrated pest management of managed plant systems. Annu. Rev. Entomol. 60, 621-645. doi: 10.1146/annurev-ento-010814-021005

Netting, A. G., Macey, M. J. K., and Barber, H. N. (1972). Chemical genetics of a sub-glaucous mutant of Brassica oleracea. Phytochemistry 11, 579-585. doi: 10.1016/0031-9422(72)80015-3

Nishida, R. (2002). Sequestration of defensive substances from plants by Lepidoptera. Annu. Rev. Entomol. 47, 57-92. doi: 10.1146/annurev.ento.47. 091201.145121

Norton, A. P., English-Loeb, G., Gadoury, D. G., and Seem, R. C. (2000). Mycophagous mites and foliar pathogens: leaf domatia mediate tritrophic interactions in grapes. Ecology 81, 490-499. doi: 10.1890/00129658(2000)081[0490:MMAFPL]2.0.CO;2

Obrist, L. B., Dutton, A., Albajes, R., and Bigler, F. (2006a). Exposure of arthropod predators to Cry1Ab toxin in Bt maize fields. Ecol. Entomol. 31, 143-154. doi: 10.1111/j.0307-6946.2006.00762.x

Obrist, L. B., Dutton, A., Romeis, J., and Bigler, F. (2006b). Biological activity of CrylAb toxin expressed by Bt maize following ingestion by herbivorous arthropods and exposure of the predator Chrysoperla carnea. BioControl 51, 31-48. doi: 10.1007/s10526-005-2936-8

Obrist, L. B., Klein, H., Dutton, A., and Bigler, F. (2005). Effects of Bt maize on Frankliniella tenuicornis and exposure of thrips predators to prey-mediated Bt toxin. Entomol. Exp. Appl. 115, 409-416. doi: 10.1111/j.1570-7458.2005. 00298.x

Obrycki, J. J., Ruberson, J. R., and Losey, J. E. (2004). "Interactions between natural enemies and transgenic insecticidal crops," in Genetics, Evolution and Biological Control, eds L. E. Ehler, R. Sforza, and T. Mateille (Wallingford: CAB International), 183-206.

Obrycki, J. J., and Tauber, M. J. (1984). Natural enemy activity on glandular pubescent potato plants in the greenhouse: an unreliable predictor of effects in the field. Environ. Entomol. 13, 679-683. doi: 10.1093/ee/13.3.679 
Obrycki, J. J., Tauber, M. J., and Tingey, W. M. (1983). Predator and parasitoid interaction with aphid-resistant potatoes to reduce aphid densities: a two-year field study. J. Econ. Entomol. 76, 456-462. doi: 10.1093/jee/76.3.456

Ode, P. J. (2006). Plant chemistry and natural enemy fitness: effects on herbivore and natural enemy interactions. Annu. Rev. Entomol. 51, 163-185. doi: 10.1146/ annurev.ento.51.110104.151110

Ode, P. J. (2013). "Plant defences and parasitoid chemical ecology," in Chemical Ecology of Insect Parasitoids, eds É Wajnberg and S. Colazza (Oxford: WileyBlackwell), 11-36.

Ode, P. J., and Crompton, D. S. (2013). Compatibility of aphid resistance in soybean and biological control by the parasitoid Aphidius colemani (Hymenoptera: Braconidae). Biol. Control 64, 255-262. doi: 10.1016/j. biocontrol.2012.12.001

Ode, P. J., Harvey, J. A., Reichelt, M., Gershenzon, J., and Gols, R. (2016). Differential induction of plant chemical defenses by parasitized and unparasitized herbivores: consequences for reciprocal, multitrophic interactions. Oikos 125, 1398-1407. doi: 10.1111/oik.03076

O'Dowd, D. J., and Willson, M. F. (1991). Associations between mites and leaf domatia. Trend Ecol. Evol. 6, 179-820.

Oerke, E.-C., and Dehne, H.-W. (2004). Safeguarding production- losses in major crops and the role of crop protection. Crop Prot. 23, 275-285. doi: 10.1016/j. cropro.2003.10.001

Orre, G. U. S., Wratten, S. D., Jonsson, M., and Hale, R. J. (2010). Effects of an herbivore-induced plant volatile on arthropods from three trophic levels in brassicas. Biol. Control 53, 62-67. doi: 10.1016/j.biocontrol.2009. 10.010

Orrell, P., and Bennett, A. E. (2013). How can we exploit above-belowground interactions to assist in addressing the challenges of food security? Front. Plant Sci. 4:432. doi: 10.3389/fpls.2013.00432

Painter, R. H. (1951). Insect Resistance in Crop Plants. Lawrence, KS: University of Kansas Press.

Panda, N., and Khush, G. S. (1995). Host Plant Resistance to Insects. Wallingford: CABI.

Páre, P. W., and Tumlinson, J. H. (1999). Plant volatiles as a defense against insect herbivores. Plant Physiol. 121, 325-331. doi: 10.1104/pp.121.2.325

Patt, J. M., and Pfannenstiel, R. S. (2008). Odor-based recognition of nectar in cursorial spiders. Entomol. Exp. Appl. 127, 64-71. doi: 10.1111/j.1570-7458. 2008.00669.x

Patt, J. M., and Pfannenstiel, R. S. (2009). Characterization of restricted area searching behavior following consumption of prey and non-prey food in a cursorial spider, Hibana futilis. Entomol. Exp. Appl. 132, 13-20. doi: 10.1111/ j.1570-7458.2009.00865.x

Paula, D. P., and Andow, D. A. (2016). Uptake and bioaccumulation of Cry toxins by an aphidophagous predator. Environ. Pollut. 209, 164-168. doi: 10.1016/j. envpol.2015.11.036

Pedigo, L. P., and Rice, M. E. (2014). Entomology and Pest Management, 6th Edn. Long Grove, IL: Waveland Press, Inc.

Pereira, A. E., Wang, H. C., Zukoff, S. N., Meinke, L. J., French, B. W., and Siegfried, B. D. (2015). Evidence of field-evolved resistance to bifenthrin in western corn rootworm (Diabrotica virgifera virgifera LeConte) populations in western Nebraska and Kansas. PLoS ONE 10:e0142299. doi: 10.1371/journal. pone.0142299

Peterson, J. A., Lundgren, J. G., and Harwood, J. D. (2011). Interactions of transgenic Bacillus thuringiensis insecticidal crops with spiders (Araneae). J. Arachnol. 39, 1-21. doi: 10.1636/M10-98.1

Peterson, J. A., Obrycki, J. J., and Harwood, J. D. (2009). Quantification of Btendotoxin exposure pathways in carabid food webs across multiple transgenic events. Biocontrol Sci. Technol. 19, 613-625. doi: 10.1080/0958315090296 8972

Peterson, J. A., Obrycki, J. J., and Harwood, J. D. (2016). Spiders from multiple functional guilds are exposed to Bt-endotoxins in transgenic corn fields via prey and pollen consumption. Biocontrol Sci. Technol. 26, 1-42. doi: 10.1080/ 09583157.2016.1193591

Pfannenstiel, R. S. (2008). Spider predators of lepidopteran eggs in south Texas field crops. Biol. Control 46, 202-208. doi: 10.1016/j.biocontrol.2008.03.011

Pfannenstiel, R. S., and Patt, J. M. (2012). Feeding on nectar and honeydew sugars improves survivorship of two nocturnal cursorial spiders. Biol. Control 63, 231-236. doi: 10.1016/j.biocontrol.2012.07.013
Pickett, J. A., Wadhams, L. J., and Woodcock, C. M. (1997). Developing sustainable pest control from chemical ecology. Agric. Ecosyst. Environ. 64, 149-156. doi: 10.1016/S0167-8809(97)00033-9

Pilcher, C. D., Obrycki, J. J., Rice, M. E., and Lewis, L. C. (1997). Preimaginal development, survival, and field abundance of insect predators on transgenic Bacillus thuringiensis corn. Environ. Entomol. 26, 446-454. doi: 10.1093/ee/26. 2.446

Pilz, C., Keller, S., Kuhlmann, U., and Toepfer, S. (2009). Comparative efficacy assessment of fungi, nematodes and insecticides to control western corn rootworm larvae in maize. BioControl 54, 671-684. doi: 10.1007/s10526-0099209-x

Pimentel, D. (1961). An evaluation of insect resistance in broccoli, Brussels sprouts, cabbage, collards and kale. J. Econ. Entomol. 54, 156-158. doi: 10.1093/jee/54. 1.156

Pimentel, D. (2005). Environmental and economic costs of the application of pesticides primarily in the United States. Environ. Dev. Sustain. 7, 229-252. doi: 10.1007/s10668-005-7314-2

Pleasants, J. M., and Oberhauser, K. S. (2013). Milkweed loss in agricultural fields because of herbicide use: effect on the monarch butterfly population. Insect Conserv. Divers. 6, 135-144. doi: 10.1111/j.1752-4598.2012.00196.x

Poelman, E. H., Broekgaarden, C., van Loon, J. J. A., and Dicke, M. (2008). Early season herbivore differentially affects plant defence responses to subsequently colonizing herbivores and their abundance in the field. Mol. Ecol. 17, 33523365. doi: 10.1111/j.1365-294X.2008.03838.x

Poelman, E. H., Bruinsma, M., Zhu, F., Weldegergis, B. T., Boursault, A. E., Jongema, Y., et al. (2012). Hyperparasitoids use herbivore-induced plant volatiles to locate their parasitoid host. PLoS Biol. 10:e1001435. doi: 10.1371/ journal.pbio.1001435

Poelman, E. H., Zheng, S.-J., Zhang, Z., Heemskerk, N. M., and Cortesero, A.-M. (2011). Parasitoid-specific induction of plant responses to parasitized herbivores affects colonization by subsequent herbivores. Proc. Natl. Acad. Sci. U.S.A. 108, 19647-19652. doi: 10.1073/pnas.1110748108

Ponsard, S., Gutierrez, A. P., and Mills, N. J. (2002). Effect of Bt-toxin (Cry1Ac) in transgenic cotton on the adult longevity of four heteropteran predators. Environ. Entomol. 31, 1197-1205. doi: 10.1603/0046-225X-31.6.1197

Poppy, G. M., and Sutherland, J. P. (2004). Can biological control benefit from genetically-modified crops? Tritrophic interactions on insect-resistant transgenic plants. Physiol. Entomol. 29, 257-268. doi: 10.1111/j.0307-6962. 2004.00382.x

Price, P. W. (1986). "Ecological aspects of host plant resistance and biological control: interactions among three trophic levels," in Interactions of Plant Resistance and Parasitoids and Predators of Insects, eds D. J. Boethel and R. D. Eikenbary (West Sussex: Ellis Horwood Limited), 11-30.

Price, P. W., Bouton, C. E., Gross, P., McPheron, B. A., Thompson, J. N., and Weis, A. E. (1980). Interactions among three trophic levels: influence of plants on interactions between insect herbivores and natural enemies. Annu. Rev. Ecol. Evol. Syst. 11, 41-65. doi: 10.1111/j.1469-8137.2008.02545.x

Rabb, R. L., and Bradley, J. R. (1968). The influence of host plants on parasitism of eggs of the tobacco hornworm. J. Econ. Entomol. 61, 1249-1252. doi: 10.1093/ jee/61.5.1249

Radcliffe, E. B., Hutchison, W. D., and Cancelado, R. E. (2009). Integrated Pest Management: Concepts, Tactics, Strategies and Case Studies. New York, NY: Cambridge University Press.

Ramirez-Romero, R., Bernal, J. S., Chaufaux, J., and Kaiser, L. (2007). Impact assessment of Bt-maize on a moth parasitoid, Cotesia marginiventris (Hymenoptera: Braconidae), via host exposure to purified Cry1 Ab protein or Bt-plants. Crop Prot. 26, 953-962. doi: 10.1016/j.cropro.2006.09.001

Rasmann, S., Köllner, T. G., Degenhardt, J., Hiltpold, I., Toepfer, S., Kuhlmann, U., et al. (2005). Recruitment of entomopathogenic nematodes by insect-damaged maize roots. Nature 434, 732-737. doi: 10.1038/nature03451

Raubenheimer, D., Mayntz, D., Simpson, S. J., and Toft, S. (2007). Nutrient-specific compensation following diapause in a predator: implications for intraguild predation. Ecology 88, 2598-2608. doi: 10.1890/07-0012.1

Ray, S., Gaffor, I., Acevedo, F. E., Helms, A., Chuang, W.-P., Tooker, J., et al. (2015). Maize plants recognize herbivore-associated cues from caterpillar frass. J. Chem. Ecol. 41, 781-792. doi: 10.1007/s10886-015-0619-1

Raymond, B., Sayyed, A. H., Hails, R. S., and Wright, D. J. (2007). Exploiting pathogens and their impact on fitness costs to manage the evolution of 
resistance to Bacillus thuringiensis. J. Appl. Ecol. 44, 768-780. doi: 10.1111/j. 1365-2664.2007.01285.x

Reina-Pinto, J. J., and Yephremov, A. (2009). Surface lipids and plant defenses. Plant Physiol. Biochem. 47, 540-549. doi: 10.1016/j.plaphy.2009.01.004

Reymond, P., Weber, H., Damond, M., and Farmer, E. E. (2000). Differential gene expression in response to mechanical wounding and insect feeding in Arabidopsis. Plant Cell 12, 707-719. doi: 10.1105/tpc.12.5.707

Riddick, E. W., and Simmons, A. M. (2014a). Do plant trichomes cause more harm than good to predatory insects? Pest Manag. Sci. 70, 1655-1665. doi: 10.1002/ps.3772

Riddick, E. W., and Simmons, A. M. (2014b). Plant trichomes have mixed impacts on predatory insects. Pest Manag. Sci. 70, 1668-1668. doi: 10.1002/ps.3811

Riederer, M., and Müller, C. (2006). Annual Plant Reviews, Biology of the Plant Cuticle. New York, NY: John Wiley \& Sons.

Roberts, A. F., Devos, Y., Lemgo, G. N. Y., and Zhou, X. G. (2015). Biosafety research for non-target organism risk assessment of RNAi-based GE plants. Front. Plant Sci. 6:958. doi: 10.3389/fpls.2015.00958

Rogers, C. E. (1985). Extrafloral nectar: entomological implications. Bull. Entomol. Soc. Am. 81, 15-20. doi: 10.1093/besa/31.3.15

Romeis, J., Dutton, A., and Bigler, F. (2004). Bacillus thuringiensis toxin (Cry1Ab) has no direct effect on larvae of the green lacewing Chrysoperla carnea (Stephens) (Neuroptera: Chrysopidae). J. Insect Physiol. 50, 175-183. doi: 10 1016/j.jinsphys.2003.11.004

Romeis, J., Meissle, M., and Bigler, F. (2006). Transgenic crops expressing Bacillus thuringiensis toxins and biological control. Nat. Biotechnol. 24, 63-71. doi: $10.1038 / \mathrm{nbt} 1180$

Rossiter, J. T., Jones, A. M., and Bones, A. M. (2003). A novel myrosinaseglucosinolate defense system in cruciferous specialist aphids. Recent Adv. Phytochem. 37, 127-142.

Roth, S. K., and Lindroth, R. L. (1995). Elevated atmospheric CO2: Effects on phytochemistry, insect performance and insect-parasitoid interactions. Glob. Chang. Biol. 1, 173-182. doi: 10.1111/j.1365-2486.1995.tb00019.x

Ruhren, S., and Handel, S. (1999). Jumping spiders (Salticidae) enhance the seed production of a plant with extrafloral nectaries. Oecologia 119, 227-230. doi: $10.1007 / \mathrm{s} 004420050780$

Rutledge, C. E., and O'Neil, R. J. (2005). Orius insidiosus (Say) as a predator of the soybean aphid, Aphis glycines Matsumura. Biol. Control 33, 56-64. doi: 10.1016/j.biocontrol.2005.01.001

Schäfer, M., Fischer, C., Meldau, S., Seebald, E., Oelmüller, R., and Baldwin, I. T. (2011). Lipase activity in insect oral secretions mediates defense responses in Arabidopsis. Plant Physiol. 156, 1520-1534. doi: 10.1104/pp.111.173567

Schellhorn, N. A., Parry, H. R., Macfadyen, S., Wang, Y., and Zalucki, M. P. (2015). Connecting scales: achieving in-field pest control from areawide and landscape ecology studies. Insect Sci. 22, 35-51. doi: 10.1111/1744-7917.12161

Schmidt, R. A. (2014). Leaf structures affect predatory mites (Acari: Phytoseiidae) and biological control: a review. Exp. Appl. Acarol. 62, 1-17. doi: 10.1007/ s10493-013-9730-6

Schoonhoven, L. M., van Loon, J. J. A., and Dicke, M. (2005). Insect-Plant Biology, 2nd Edn. Oxford: Oxford University Press.

Schuler, T. H., Potting, R. P., Denholm, I., and Poppy, G. M. (1999). Parasitoid behaviour and Bt plants. Nature 400, 825-826. doi: 10.1038/23605

Schuster, M. F., and Calderon, M. (1986). "Interactions of host plant resistant genotypes and beneficial insects in cotton ecosystems," in Interactions of Plant Resistance and Parasitoids and Predators of Insects, eds D. J. Boethel and R. D. Eikenbary (New York, NY: Wiley), 84-97.

Schuster, M. F., Calvin, P. D., and Langston, W. C. (1983). "Interaction of high tannin with bollworm control by Pydrin and Dipel," in Proceedings of the 1983 Beltwide Cotton Production Research Conference, ed. J. M. Brown (Memphis, TN: National Cotton Council of America), 72-73.

Schuster, M. F., Lukefahr, M. J., and Maxwell, F. G. (1976). Impact of nectariless cotton on plant bugs and natural enemies. J. Econ. Entomol. 69, 400-402. doi: $10.1093 /$ jee/69.3.400

Sétamou, M., Bernal, J. S., Legaspi, J. C., and Mirkov, T. E. (2002a). Effects of snowdrop lectin (Galanthus nivalis agglutinin) expressed in transgenic sugarcane on fitness of Cotesiaflavipes (Hymenoptera: Braconidae), a parasitoid of the nontarget pest Diatraea saccharalis (Lepidoptera: Crambidae). Ann. Entomol. Soc. Am. 95, 75-83. doi: 10.1603/0013-8746(2002)095[0075: EOSLGN]2.0.CO;2
Sétamou, M., Bernal, J. S., Legaspi, J. C., and Mirkov, T. E. (2002b). Parasitism and location of sugarcane borer (Lepidoptera: Pyralidae) by Cotesia flavipes (Hymenoptera: Braconidae) on transgenic and conventional sugarcane. Environ. Entomol. 31, 1219-1225. doi: 10.1603/0046-225X-31.6.1219

Sétamou, M., Bernal, J. S., Legaspi, J. C., Mirkov, T. E., and Legaspi, B. C. Jr. (2002c). Evaluation of lectin-expressing transgenic sugarcane against stalkborers (Lepidoptera: Pyralidae): effects on life history parameters. J. Econ. Entomol. 95, 469-477. doi: 10.1603/0022-0493-95.2.469

Settle, W. H., Ariawan, H., Astuti, E. T., Cahyana, W., Hakim, A. L., Hindayana, D., et al. (1996). Managing tropical rice pests through conservation of generalist natural enemies and alternative prey. Ecology 77, 1975-1988. doi: 10.2307/ 2265694

Simpson, M., Gurr, G. M., Simmons, A. T., Wratten, S. D., James, D. G., Leeson, G., et al. (2011a). Field evaluation of the 'attract and reward' biological control approach in vineyards. Ann. Appl. Biol. 159, 69-78. doi: 10.1111/j.1744-7348. 2011.00477.x

Simpson, M., Gurr, G. M., Simmons, A. T., Wratten, S. D., James, D. G., Leeson, G., et al. (2011b). Attract and reward: combining chemical ecology and habitat manipulation to enhance biological control in field crops. J. Appl. Ecol. 48, 580-590. doi: 10.1111/j.1365-2664.2010.01946.x

Siomi, H., and Siomi, M. C. (2009). On the road to reading the RNA-interference code. Nature 457, 396-404. doi: 10.1038/nature07754

Smiley, J. (1986). Ant constancy at Passiflora extrafloral nectaries: effects on caterpillar survival. Ecology 67, 516-521. doi: 10.2307/1938594

Smith, C. M. (2005). Plant Resistance to Arthropods: Molecular and Conventional Approaches. Dordrecht: Springer-Verlag.

Soler, R., Harvey, J. A., Kamp, A. F. D., Vet, L. E. M., van der Putten, W. H., van Dam, N. M., et al. (2007). Root herbivores influence the behaviour of an aboveground parasitoid through changes in plant volatile signals. Oikos 116, 367-376. doi: 10.1111/j.0030-1299.2007.15501.x

Soler, R., van der Putten, W. H., Harvey, J. A., Vet, L. E. M., Dicke, M., and Bezemer, T. M. (2012). Root herbivore effects on aboveground multitrophic interactions: patterns, processes and mechanisms. J. Chem. Ecol. 38, 755-767. doi: $10.1007 / \mathrm{s} 10886-012-0104-\mathrm{z}$

Southwood, R. (1986). "Plant surfaces and insects- an overview," in Insects and the Plant Surface, eds B. Juniper and R. Southwood (London: Edward Arnold), $1-22$.

Stadler, B., and Mackauer, M. (1996). Influence of plant quality on interactions between the aphid parasitoid Ephedrus californicus (Baker) (Hymenoptera: Aphidiidae) and its host, Acyrthosiphon pisum (Harris) (Homoptera: Aphididae). Can. Entomol. 128, 27-39. doi: 10.4039/Ent12827-1

Stapel, J. O., Cortesero, A. M., De Moraes, C. M., Tumlinson, J. H., and Lewis, W. J. (1997). Effects of extrafloral nectar, honeydew and sucrose on searching behavior and efficiency of Microplitis croceipes (Hymenoptera: Braconidae) in cotton. Environ. Entomol. 26, 617-623. doi: 10.1093/ee/26.3.617

Stavrinides, M. C., and Skirvin, D. J. (2003). The effect of chrysanthemum leaf trichome density and prey spatial distribution on predation of Tetranychus urticae (Acari: Tetranychidae) by Phytoseiulus persimilis (Acari: Phytoseiidae). Bull. Entomol. Res. 93, 343-350. doi: 10.1079/BER2003243

Stephenson, A. G. (1982). The role of extrafloral nectaries of Catalpa speciosa in limiting herbivory and increasing fruit production. Ecology 63, 663-669. doi: $10.2307 / 1936786$

Stern, V. M., Smith, R. F., van den Bosch, R., and Hagen, K. S. (1959). The integrated control concept. Hilgardia 29, 81-101. doi: 10.3733/hilg.v29n0 $2 \mathrm{p} 081$

Stout, M. J. (2013). Reevaluating the conceptual framework for applied research on host-plant resistance. Insect Sci. 20, 263-272. doi: 10.1111/1744-7917. 12011

Stout, M. J., Workman, K. V., Bostock, R. M., and Duffey, S. S. (1998). Specificity of induced resistance in the tomato, Lycopersicon esculentum. Oecologia 113, 74-81. doi: 10.1007/s004420050355

Sudhakar, D., Fu, X. D., Stoger, E., Williams, S., Spence, J., Brown, D. P., et al. (1998). Expression and immunolocalisation of the snowdrop lectin, GNA in transgenic rice plants. Transgenic Res. 7, 371-378. doi: 10.1023/A: 1008856703464

Sun, Y.-C., Li, F., Gao, F., and Ge, F. (2011). Effects of elevated CO2 and plant genotype on interactions among cotton, aphids and parasitoids. Insect Sci. 18, 451-461. doi: 10.1111/j.1744-7917.2010.01328.x 
Sunderland, K. D., Fraser, A. M., and Dixon, A. F. G. (1986). Field and laboratory studies on money spiders (Linyphiidae) as predators of cereal aphids. J. Appl. Ecol. 24, 907-933. doi: 10.2307/2403989

Taylor, R. M., and Pfannenstiel, R. S. (2008). Nectar feeding by wandering spiders on cotton plants. Environ. Entomol. 37, 996-1002. doi: 10.1093/ee/37.4.996

Taylor, R. M., and Pfannenstiel, R. S. (2009). How dietary plant nectar affects the survival, growth, and fecundity of a cursorial spider Cheiracanthium inclusum (Araneae: Miturgidae). Environ. Entomol. 38, 1379-1386. doi: 10.1603/022.038. 0505

Thomas, M., and Waage, J. (1996). Integration of Biological Control and Host Plant Resistance Breeding: A Scientific and Literature Review. Wageningen: Technical Centre for Agricultural and Rural Cooperation (CTA).

Thorbek, P., Sunderland, K. D., and Topping, C. J. (2004). Reproductive biology of agrobiont linyphiid spiders in relation to habitat, season and biocontrol potential. Biol. Control 30, 193-202. doi: 10.1016/j.biocontrol.2003.10.004

Tian, D., Peiffer, M., Shoemaker, E., Tooker, J. F., Haubruge, E., Francis, F., et al. (2012). Salivary glucose oxidase from caterpillars mediates the induction of rapid and delayed-induced defenses in the tomato plant. PLoS ONE 7:e41947. doi: 10.1371/journal.pone. 0036168

Tian, J. C., Liu, Z. C., Chen, M., Chen, Y., Chen, X. X., Peng, Y. F., et al. (2010). Laboratory and field assessments of prey-mediated effects of transgenic $\mathrm{Bt}$ rice on Ummeliata insecticeps (Araneida: Linyphiidae). Environ. Entomol. 39, 1369-1377. doi: 10.1603/EN10003

Tian, J. C., Wang, X. P., Long, L. P., Romeis, J., Naranjo, S. E., Hellmich, R. L., et al. (2014). Eliminating host-mediated effects demonstrates Bt maize producing CrylF has no adverse effects on the parasitoid Cotesia marginiventris. Transgenic Res. 23, 257-264. doi: 10.1007/s11248-013-9748-x

Tingey, W. M. (1982). "Potential for plant resistance in management of arthropod pests," in Advances in Potato Pest Management, eds J. H. Lashomb and R. A. Casagrande (Stroudsburg, PA: Hutchinson Ross), 268-288.

Toepfer, S., Gueldenzoph, C., Ehlers, R.-U., and Kuhlmann, U. (2005). Screening of entomopathogenic nematodes for virulence against the invasive western corn rootworm, Diabrotica virgifera virgifera (Coleoptera: Chrysomelidae) in Europe. Bull. Entomol. Res. 95, 473-482. doi: 10.1079/BER2005379

Toepfer, S., Peters, A., Ehlers, R.-U., and Kuhlmann, U. (2008). Comparative assessment of the efficacy of entomopathogenic nematode species at reducing western corn rootworm larvae and root damage in maize. J. Appl. Entomol. 132, 337-348. doi: 10.1111/j.1439-0418.2008.01274.x

Tooker, J. F., Peiffer, M., Luthe, D. S., and Felton, G. W. (2010). Trichomes as sensors: detecting activity on the leaf surface. Plant Signal. Behav. 5, 73-75. doi: $10.4161 /$ psb.5.1.10234

Torres, J. A., and Ruberson, J. R. (2006). Interactions of Bt-cotton and the omnivorous bigeyed bug Geocoris punctipes (Say), a key predator in cotton fields. Biol. Control 39, 47-57. doi: 10.1016/j.biocontrol.2006.03.006

Torres, J. B., Ruberson, J. R., and Adang, M. J. (2006). Expression of Bacillus thuringiensis CrylAc protein in cotton plants, acquisition by pests and predators: a tritrophic analysis. Agric. For. Entomol. 8, 191-202. doi: 10.1111/ j.1461-9563.2006.00298.x

Treacy, M. F., Benedict, J. H., Walmsley, M. H., Lopez, J. D., and Morrison, R. K. (1987). Parasitism of bollworm (Lepidoptera: Noctuidae) eggs on nectaried and nectariless cotton. Environ. Entomol. 16, 420-423. doi: 10.1093/ee/16.2.420

Trichilo, P. J., and Leigh, T. F. (1986). Predation on spider mite eggs by the western flower thrips, Frankliniella occidentalis (Thysanoptera: Thripidae), an opportunist in a cotton agroecosystem. Environ. Entomol. 15, 821-825. doi: 10.1007/s10493-013-9711-9

Turlings, T. C. J., Bernasconi, M., Bertossa, R., Bigler, F., Caloz, G., and Dorn, S. (1998). The induction of volatile emissions in maize by three herbivore species with different feeding habits: possible consequences for their natural enemies. Biol. Control 11, 122-129. doi: 10.1006/bcon.1997.0591

Turlings, T. C. J., and Wäckers, F. L. (2004). "Recruitment of predators and parasitoids by herbivore-injured plants," in Advances in Insect Chemical Ecology, eds R. T. Cardé and J. Millar (Cambridge: Cambridge University Press), 21-75.

United Nations (2004). World Population to 2300. Available at: http://www.un.org/ esa/population/publications/longrange2/WorldPop2300final.pdf

United States Department of Agriculture National Agricultural Statistics Service (2015). Acreage report. Available at: http://www.usda.gov/nass/PUBS/ TODAYRPT/acrg0615.pdf van Dam, N. M., and Heil, M. (2011). Multitrophic interactions above and below ground: en route to the next level. J. Ecol. 99, 77-88. doi: 10.1111/j.1365-2745. 2010.01761.x

van Emden, H. F. (1988). The potential for managing indigenous natural enemies of aphids on field crops. Philos. Trans. R. Soc. Lond. B 318, 183-201. doi: 10.1098/rstb.1988.0004

van Emden, H. F. (1991). The role of host plant resistance in insect pest mismanagement. Bull. Entomol. Res. 81, 123-126. doi: 10.1017/ S0007485300051166

van Lenteren, J. C. (2012). IOBC Internet Book of Biological Control, version 6. International Organization for Biological Control. Available at: http://www.iobcglobal.org/download/IOBC_InternetBookBiCoVersion6Spring2012.pdf

Van Zandt, P. A., and Agrawal, A. A. (2004). Specificity of induced plant responses to specialist herbivores of the common milkweed Asclepias syriaca. Oikos 104, 401-409. doi: 10.1111/j.0030-1299.2004.12964.x

Verkerk, R. H. J., and Wright, D. J. (1996). Common cabbage resistance mechanisms against the diamondback moth: still an open book? Ann. Appl. Biol. 128, 571-577. doi: 10.1111/j.1744-7348.1996.tb07116.x

Vet, L. E. M., and Dicke, M. (1992). Ecology of infochemical use by natural enemies in a tritrophic context. Annu. Rev. Entomol. 37, 141-172. doi: 10.1146/annurev. en.37.010192.001041

Vojtech, E., Meissle, M., and Poppy, G. M. (2005). Effects of Bt maize on the herbivore Spodoptera littoralis (Lepidoptera: Noctuidae) and the parasitoid Cotesia marginiventris (Hymenoptera: Braconidae). Transgenic Res. 14, 133144. doi: 10.1007/s11248-005-2736-Z

von Berg, K., Traugott, M., Symondson, W. O. C., and Scheu, S. (2008). Impact of abiotic factors on predator-prey interactions: DNA-based gut content analysis in a microcosm experiment. Bull. Entomol. Res. 98, 257-261. doi: 10.1017/ S0007485308006007

von Mérey, G. E., Veyrat, N., de Lange, E., Degen, T., Mahuku, G., Valdez, R. L., et al. (2012). Minor effects of two elicitors of insect and pathogen resistance on volatile emissions and parasitism of Spodoptera frugiperda in Mexican maize fields. Biol. Control 60, 7-15. doi: 10.1016/j.biocontrol.2011.09.010

von Mérey, G. E., Veyrat, N., Mahuku, G., Valdez, R. L., Turlings, T. C. J., and D'Alessandro, M. (2011). Dispensing synthetic green leaf volatiles in maize fields increases the release of sesquiterpenes by the plants, but has little effect on the attraction of pest and beneficial insects. Phytochemistry 72, 1838-1847. doi: 10.1016/j.phytochem.2011.04.022

Wäckers, F. L., and Bonifay, C. (2004). How to be sweet? Extrafloral nectar allocation by Gossypium hirsutum fits optimal defense theory predictions. Ecology 85, 1512-1518. doi: 10.1890/03-0422

Wäckers, F. L., Zuber, D., Wunderlin, R., and Keller, F. (2001). The effect of herbivory on temporal and spatial dynamics of extrafloral nectar production in cotton and castor. Ann. Bot. 87, 365-370. doi: 10.1006/anbo.2000.1342

Walde, S. (1995). How quality of host plant affects a predator-prey interaction in biological control. Ecology 76, 1206-1219. doi: 10.2307/1940927

Walker, G. P., Cameron, P. J., MacDonald, F. M., Madhusudhan, V. V., and Wallace, A. R. (2007). Impacts of Bacillus thuringiensis toxins on parasitoids (Hymenoptera: Braconidae) of Spodoptera litura and Helicoverpa armigera (Lepidoptera: Noctuidae). Biol. Control 40, 142-151. doi: 10.1016/j.biocontrol. 2006.09.008

Walling, L. L. (2000). The myriad of plant responses to herbivores. J. Plant Growth Regul. 19, 195-216.

Walter, D. E. (1996). Living on leaves: mites, tomentia, and leaf domatia. Annu. Rev. Entomol. 41, 101-114. doi: 10.1146/annurev.en.41.010196.000533

Wang, Z. Y., Zhang, K. W., Sun, X. F., Tang, K. X., and Zhang, J. R. (2005). Enhancement of resistance to aphids by introducing the snowdrop lectin gene GNA into maize plants. J. Biosci. 30, 627-638. doi: 10.1007/BF02703563

Wangila, D. S., Gassmann, A. J., Petzold-Maxwell, J. L., French, B. W., and Meinke, L. J. (2015). Susceptibility of Nebraska western corn rootworm (Coleoptera: Chrysomelidae) populations to Bt corn events. J. Econ. Entomol. 108, 742-751. doi: $10.1093 /$ jee/tou063

Wäschke, N., Meiners, T., and Rostás, M. (2013). "Foraging strategies of parasitoids in complex chemical environments," in Chemical Ecology of Insect Parasitoids, eds É Wajnberg and S. Colazza (Oxford: John Wiley \& Sons), 37-63.

Wei, W., Schuler, T. H., Clark, S. J., Stewart, C. N., and Poppy, G. M. (2008). Movement of transgenic plant-expressed Bt CrylAc proteins through high 
trophic levels. J. Appl. Entomol. 132, 1-11. doi: 10.1111/j.1439-0418.2007. 01242.x

White, J. A., and Andow, D. A. (2005). Host-parasitoid interactions in a transgenic landscape: spatial proximity effects of host density. Environ. Entomol. 34, 1493-1500. doi: 10.1603/0046-225X-34.6.1493

Wilson, L. J., Bauer, L. R., and Walter, G. H. (1996). 'Phytophagous' thrips are facultative predators of two-spotted spider mites (Acari: Tetranychidae) on cotton in Australia. Bull. Entomol. Res. 86, 297-305. doi: 10.1017/ S0007485300052597

Winder, L. (1990). Predation of the cereal aphid Sitobion avenae by polyphagous predators on the ground. Ecol. Entomol. 15, 105-110. doi: 10.1111/j.1365-2311. 1990.tb00789.x

Winder, L., Hirst, D. J., Carter, N., Wratten, S. D., and Sopp, P. I. (1994). Estimating predation on the grain aphid Sitobion avenae by polyphagous predators. J. Appl. Ecol. 31, 1-12. doi: 10.2307/2404594

Wiseman, B. R., and Davis, F. M. (1990). Plant-resistance to insects attacking corn and grain-sorghum. Fla. Entomol. 73, 446-458. doi: 10.2307/3495461

Wittstock, U., Agerbirk, N., Stauber, E. J., Olsen, C. E., Hippler, M., MitchellOlds, T., et al. (2004). Successful herbivore attack due to metabolic diversion of a plant chemical defense. Proc. Natl. Acad. Sci. U.S.A. 101, 4859-4864. doi: 10.1073/pnas.0308007101

Wolfenbarger, L. L., Naranjo, S. E., Lundgren, J. G., Bitzer, R. J., and Watrud, L. S. (2008). Bt crop effects on functional guilds of non-target arthropods: a meta-analysis. PLoS ONE 3:e2118. doi: 10.1371/journal.pone.0002118

Wright, R. J., Thaxton, P. M., El-Zik, K. M., and Paterson, A. H. (1999). Molecular mapping of genes affecting pubescence of cotton. J. Heredity 90, 215-219. doi: 10.1093/jhered/90.1.215

Wright, R. J., Witkowski, J. F., Echtenkamp, G., and Georgis, R. (1993). Efficacy and persistence of Steinernema carpocapsae (Rhabditida: Steinernematidae) applied through a center-pivot irrigation system against larval corn rootworms (Coleoptera: Chrysomelidae). J. Econ. Entomol. 86, 1348-1354. doi: 10.1093/jee/ 86.5.1348

Wu, K.-M., Lu, Y.-H., Feng, H.-Q., Jiang, Y.-Y., and Zhao, J.-Z. (2008). Suppression of cotton bollworm in multiple crops in China in areas for Bt toxin-containing cotton. Science 321, 1676-1678. doi: 10.1126/science.116 0550

Zhangsun, D., Luo, S., Chen, R., and Tang, K. (2007). Improved Agrobacteriummediated genetic transformation of GNA transgenic sugarcane. Biologia 62, 386-393. doi: 10.2478/s11756-007-0096-2

Zwahlen, C., and Andow, D. A. (2005). Field evidence for the exposure of ground beetles to Cry1Ab from transgenic corn. Environ. Biosafety Res. 4, 113-117. doi: 10.1051/ebr:2005014

Conflict of Interest Statement: The authors declare that the research was conducted in the absence of any commercial or financial relationships that could be construed as a potential conflict of interest.

The reviewers JG and $\mathrm{AB}$ and handling Editor declared their shared affiliation, and the handling Editor states that the process nevertheless met the standards of a fair and objective review.

Copyright (c) 2016 Peterson, Ode, Oliveira-Hofman and Harwood. This is an openaccess article distributed under the terms of the Creative Commons Attribution License (CC BY). The use, distribution or reproduction in other forums is permitted, provided the original author(s) or licensor are credited and that the original publication in this journal is cited, in accordance with accepted academic practice. No use, distribution or reproduction is permitted which does not comply with these terms. 